\title{
In Vivo Expansion of Regulatory T Cells with IL-2/IL-2 Antibody Complex Protects against Transient Ischemic Stroke
}

\author{
Haiyue Zhang, ${ }^{1 \star}$ Yuguo Xia, ${ }^{1 \star}$ Qing Ye, ${ }^{1}$ Fang Yu, ${ }^{1}$ Wen Zhu, ${ }^{1}$ Peiying Li,${ }^{1}$ Zhishuo Wei, ${ }^{1}$ Yuanyuan Yang, ${ }^{1}$ Yejie Shi, ${ }^{1}$ \\ Angus W. Thomson, ${ }^{2} \oplus^{-}$Jun Chen, ${ }^{1,3}$ and ${ }^{\circledR X}$ Xiaoming $\mathrm{Hu}^{1,3}$ \\ ${ }_{1}^{1}$ Pittsburgh Institute of Brain Disorders and Recovery, and Department of Neurology, ${ }^{2}$ Starzl Transplantation Institute, Department of Surgery and \\ Department of Immunology, University of Pittsburgh School of Medicine, Pittsburgh, Pennsylvania 15213, and ${ }^{3}$ Geriatric Research, Education and Clinical \\ Center, Veterans Affairs Pittsburgh Healthcare System, Pittsburgh, Pennsylvania 15261
}

Regulatory T cells (Tregs) are known to protect against ischemic stroke. However, the low frequency of Tregs restricts their clinical utility. This study investigated whether expanding the number of Tregs in vivo with the IL-2/IL-2 antibody complex (IL-2/IL-2Ab) could improve stroke outcomes and further elaborated the mechanisms of protection in male mice. C57BL/6 mice received IL-2/IL-2Ab or isotype IgG (IsoAb) intraperitoneally for $3 \mathrm{~d}$ before (pretreatment) or starting $2 \mathrm{~h}$ after (posttreatment) $60 \mathrm{~min}$ middle cerebral artery occlusion (MCA0). IL-2/IL-2Ab selectively increased the number of Tregs in the blood, spleen, and lymph nodes. The IL-2/IL-2Ab treatment significantly reduced infarct volume, inhibited neuroinflammation, and improved sensorimotor functions, as manifested by rotarod test and foot fault test, compared with IsoAb-treated stroke mice. Treg depletion was then achieved by diphtheria toxin (DT) injection into transgenic mice expressing the DT receptor under the control of the Foxp3 promoter (DTR mice). The depletion of Tregs completely eliminated IL-2/IL-2Ab-afforded neuroprotection. Interestingly, adoptive transfer of Tregs collected from IL-2/IL-2Ab-treated mice demonstrated more potent neuroprotection than an equal number of Tregs prepared from IsoAb-treated mice, suggesting that IL-2/IL$2 \mathrm{Ab}$ not only elevated Treg numbers, but also boosted their functions. Mechanistically, IL-2/IL-2Ab promoted the expression of CD39 and CD73 in expanded Tregs. CD73 deficiency diminished the protective effect of IL-2/IL-2Ab-stimulated Tregs in stroke mice. The results show that IL-2/IL-2Ab expands Tregs in vivo and boosts their immunomodulatory function. The activation of CD39/CD73 signaling in Tregs may participate as a potential mechanism underlying IL-2/IL-2Ab-afforded neuroprotection against ischemic brain injury.

Key words: cerebral ischemia; IL-2/IL-2 antibody complex; neuroprotection; regulatory T cells

Significance Statement

Regulatory T cells (Tregs) are known to protect against ischemic stroke. However, the low frequency of Tregs restricts their clinical utility. This study reported that systemic administration of the IL-2/IL-2 antibody complex (IL-2/IL-2Ab) robustly and selectively expanded the number of Tregs after stroke. IL-2/IL-2Ab pretreatment or posttreatment significantly improved stroke outcomes in a rodent model of ischemic stroke. We further discovered that IL-2/IL-2Ab not only elevated Treg numbers, but also boosted their functions and enhanced the expression of CD39 and CD73. Using CD73-deficient mice, we confirmed the importance of CD73 in the protective effect of IL-2/IL-2Ab-stimulated Tregs in stroke mice. These results shed light on IL-2/IL-2Ab as a clinically feasible immune therapy to boost endogenous Treg responses and ameliorate ischemic brain injury.

\section{Introduction}

Recent research findings have shown that regulatory $\mathrm{T}$ cells (Tregs) may serve as endogenous regulators to control immune

Received Oct. 6, 2017; revised Aug. 11, 2018; accepted Sept. 8, 2018.

Author contributions: H.Z. and Y.X. wrote the first draft of the paper; Q.Y., W.Z., P.I., Z.W., Y.S., A.W.T., and J.C. edited the paper; A.W.T., J.C., and X.H. designed research; H.Z., Y.X., Q.Y., F.Y., W.Z., P.I., Z.W., and Y.Y. performed research; H.Z., Y.X., F.Y., P.I., Y.Y., and X.H. analyzed data; X.H. wrote the paper.

This work was supported by grants from the National Institutes of Health-National Institute of Neurological Disorders and Stroke (Grants NS094573 and NS092618 to X.H. and Grant NS105430 to J.C.). J.C. is a recipient of the VA Senior Research Career Scientist Award. We thank Carol Culver for editorial assistance.

The authors declare no competing financial interests. responses in the ischemic brain (Liesz et al., 2009; Li et al., 2013; Wang et al., 2015). Tregs are a specialized subset of T lympho-

\footnotetext{
*H.Z. and Y.X. contributed equally to this work.

H. Zhang's present affiliation: Department of Neurology, Xuanwu Hospital, Capital Medical University, Beijing, China.

Correspondence should be addressed to either of the following: Dr. Xiaoming Hu, Pittsburgh Institute of Brain Disorders and Recovery, and Department of Neurology, University of Pittsburgh School of Medicine, 200 Lothrop Street, SBST 506, Pittsburgh, PA 15213, E-mail: hux2@upmc.edu; or Dr. Jun Chen, Pittsburgh Institute of Brain Disorders and Recovery, and Department of Neurology, University of Pittsburgh School of Medicine, Pittsburgh, PA 15213, E-mail: chenj2@upmc.edu.

https://doi.org/10.1523/JNEUROSCI.3411-17.2018

Copyright $\odot 2018$ the authors $\quad 0270-6474 / 18 / 3810168-12 \$ 15.00 / 0$
} 
cytes, described originally as $\mathrm{CD} 4{ }^{+} \mathrm{T}$ cells that constitutively express CD25. Functional Tregs are further defined by the expression of a key transcription factor known as forkhead box P3 (FoxP3) (Hori et al., 2003; Fontenot and Rudensky, 2005). Tregs play a key role in suppressing the activation of the immune system and thereby maintain immune homeostasis, prevent autoimmunity, and modulate inflammation induced by pathogens or environmental toxins. Disruptions of Treg function result in a shift of immune homeostasis toward inflammation and autoimmunity. Clinical studies have shown that the number of circulating Tregs decreases soon after stroke, which is followed by a significant increase for several weeks (Urra et al., 2009; Yan et al., 2009; Mao et al., 2017). In support of a protective role of Tregs in stroke, depletion of Tregs from the circulation resulted in enhanced tissue loss and worsened functional outcomes $7 \mathrm{~d}$ after middle cerebral artery occlusion (MCAO) (Liesz et al., 2009). Later studies demonstrated the neuroprotective effects of adoptive Treg therapy that are mediated through restricting inflammatory dysregulation, ameliorating neurovascular disruption, and enhancing brain repair (Li et al., 2013; Wang et al., 2015). Remarkably, the early protective effect of Tregs does not require passage across the blood-brain barrier. Tregs provide early CNS protection by ameliorating the deleterious activities of peripheral immune cells rather than directly affecting CNS cells (Li et al., 2013, 2014).

The clinical application of Tregs as a cell therapy requires the isolation of sufficient numbers of cells from the blood. However, the Treg subset represents only $5-10 \%$ of circulating $\mathrm{CD} 4{ }^{+} \mathrm{T}$ cells (Battaglia et al., 2006; Trzonkowski et al., 2009). The low number of Tregs restricts their clinical utility as a cell therapy for stroke. There is considerable interest in the idea of transferring Tregs after ex vivo or in vivo expansion (Tang et al., 2004; Golshayan et al., 2007). IL-2 is a cytokine known to induce T-cell proliferation (Shevach, 2012). Interestingly, the complex of IL-2 with a specific anti-IL-2 antibody JES6-1 (2:1 molar ratio) can induce selective expansion of Tregs by blocking the binding site on IL-2 that is needed for the expansion of other T cells (Shevach, 2012). In addition, the IL-2/IL-2Ab complex extends the half-life of IL-2 and results in enhanced biological activity (Tomala et al., 2009). Injection of IL-2/IL-2Ab for a short period of time has been shown to expand the number of Tregs in multiple organs. In vivo-expanded Tregs are effective in treating autoimmune diseases and reducing transplantation rejection (Webster et al., 2009; Koreth et al., 2011). The effect of IL-2/IL-2Ab complexes in stroke has not been thoroughly evaluated.

In this study, we evaluated the protective effect of IL-2/IL-2Ab on a mouse model of stroke and further explored the mechanisms of protection. We found that IL-2/IL-2Ab treatment reduced brain infarct and ameliorated neurological deficits after transient MCAO (tMCAO). Furthermore, our results revealed that IL-2/ IL-2Ab complex not only increased the number of Tregs, but also significantly enhanced their function. The elevation of CD73 expression on expanded Tregs is critical for the protective effects of the IL-2/IL-2Ab complex in the ischemic brain. Our findings suggest that IL-2/IL-2Ab treatment is a novel and clinically feasible immunotherapy to boost Treg population in vivo and to protect against ischemic brain injury.

\section{Materials and Methods}

Animal model. All animal experiments were approved by the University of Pittsburgh Institutional Animal Care and Use Committee and were performed in accordance with the standards outlined in the National Institutes of Health's Guide for the Care and Use of Laboratory Animals.
Wild-type (WT) C57BL/6, CD73 knock-out (KO), or Foxp3-DTR male mice (8-12 weeks of age, 25-30 g body weight; The Jackson Laboratory) were randomly assigned to sham or tMCAO groups with different treatments using a lottery drawing box. Selective Foxp $3^{+}$Treg depletion was achieved in Foxp3-DTR mice by diphtheria toxin (DT, i.p., $0.05 \mu \mathrm{g} / \mathrm{g}$ body weight) administration (Kim et al., 2007). The murine ischemic model was induced by $60 \mathrm{~min}$ MCAO as described previously (Yang et al., 2017). Sham-operated animals underwent the same procedure without MCAO induction. Rectal temperature was maintained at $37.0 \pm$ $0.5^{\circ} \mathrm{C}$ during the entire procedure using a temperature-controlled heating pad. Regional cerebral blood flow (rCBF) was monitored using laser Doppler flowmetry. Animals that died or failed to reduce at least $75 \%$ of rCBF were excluded from further experiments. Experiments were performed by an investigator blinded to experimental group assignments.

A grand total of 293 mice ( 23 sham-operated and 270 ischemic mice) were used in this study, including 22 mice that were excluded from further assessments either because of death after ischemia or failure of ischemia induction. Mortality during tMCAO surgery was 5.2\% in WT mice (11/213), $5.9 \%$ in CD73 KO mice (1/17), and $14.7 \%$ in DTR mice $(5 / 34)$.

Intraperitoneal injection of IL-2/IL-2-Ab complex. Recombinant murine IL-2 protein and anti-mouse IL-2 mAbs (JES6-1) were purchased from eBioscience. IL-2 protein was mixed with anti-IL-2 at a 2:1 molar ratio $(1 \mu \mathrm{g}$ of recombinant murine IL-2 protein and $5 \mu \mathrm{g}$ of anti-IL-2 $\mathrm{mAbs}$ ) (Shevach, 2012) and incubated at $37^{\circ} \mathrm{C}$ for $30 \mathrm{~min}$. Complex or rat IgG isotype control was intraperitoneally injected into mice for 3 consecutive days.

Single-cell suspension and flow cytometry. Single-cell suspensions were prepared from spleen, lymph nodes, blood, and brain (Li et al., 2013). Isolated cells were resuspended at $1 \times 10^{6} / \mathrm{ml}$ and stained with fluorophore-labeled antibodies (CD4, CD3, CD8, Gr1, B220, CD25, Foxp3, CD73, or CD39) following the manufacturer's instructions (eBioscience). For Foxp3 intracellular staining, cells were surface stained with anti-CD4, anti-CD25, anti-CD39, or anti-CD73. Cells were then permeabilized with the intracellular staining kit (eBioscience), followed by staining with anti-Foxp3. Flow cytometric analysis was performed using an LSRII flow cytometer (BD Biosciences).

Treg isolation and adoptive transfer. Spleen, inguinal, and axillary lymph nodes were harvested to prepare single-cell suspensions. $\mathrm{CD} 4{ }^{+} \mathrm{CD} 25^{+}$Tregs were isolated using a mouse Treg isolation kit (Miltenyi Biotec) according to the manufacturer's instructions. A total of $1 \times 10^{6}$ freshly isolated Tregs were transferred intravenously to recipient mice $2 \mathrm{~h}$ after tMCAO through tail vein.

Measurement of brain infarct. Brain infarct volume was measured by 2,3,5-triphenyltetrazolium (TTC) or MAP2 staining. Images were analyzed using ImageJ by an investigator who was blinded to experimental group assignment. Infarct volume was calculated by adding up the infarct areas (contralateral area - ipsilateral side noninfarct area) of seven consecutive slices.

Behavioral tests. The rotarod test was used to evaluate motor functional change as described previously (Yang et al., 2017). Briefly, mice were forced to run on a rotating drum (IITC Life Science) with speeds starting at $4 \mathrm{rpm}$ and accelerating to $40 \mathrm{rpm}$ in $300 \mathrm{~s}$. Three consecutive trials were conducted for each mouse with an interval of $15 \mathrm{~min}$. The time at which a mouse fell off the drum was recorded as the latency to fall. The foot fault test was performed to assess forelimb and hindlimb function. Mice placed their paws on a wire while moving on an elevated grid surface. A foot fault was recorded when a paw slipped. Each animal was tested for 3 trials lasting $1 \mathrm{~min}$ each. The data are expressed as the percentage of errors made by the contralateral limbs versus the total steps.

Immunohistochemistry and analysis. Brain sections $(25 \mu \mathrm{m})$ were incubated with primary antibodies at $4{ }^{\circ} \mathrm{C}$ overnight. Primary antibodies included: rabbit anti-CD3 (Abcam), rat anti-F4/80 (BM8, BioLegend), rabbit anti-NeuN (Millipore), and rabbit anti-MAP2 (Santa Cruz Biotechnology). After three washes in PBS, sections were incubated with fluorescently labeled secondary antibody (Jackson ImmunoResearch Laboratories) for $1 \mathrm{~h}$ at room temperature. The process was repeated once for double staining. Sections were then washed and mounted with DAPI Fluoromount-G (Southern Biotech). For neuronal death analysis, 
terminal deoxynucleotidyl transferase dUTP nick end labeling (TUNEL) was processed after NeuN labeling according to instructions from the manufacturer (In Situ Cell Death Detection Fluorescein, Roche, catalog $\# 11684795910$ ). Fluorescence images were acquired using confocal microscopy (FV1000, Olympus). Images were processed with ImageJ by a blinded observer for the unbiased counting of automatically recognized cells. Positively stained cells were counted from one microscopic field in the cortex and two in the striatum of each section. Three sections were analyzed for each brain. Data are expressed as mean numbers of cells per square millimeter.

$R T-P C R$. Total RNA was extracted from cerebral tissues (ischemic hemisphere or sham) using the RNeasy Lipid Tissue Mini Kit (Qiagen) and reverse transcribed into cDNA using the Superscript III First-Strand Synthesis Supermix (Invitrogen) according to the manufacturer's instructions. PCR was conducted on the Opticon 2 Real-Time PCR Detection System (Bio-Rad) using corresponding primers and SYBR gene PCR Master Mix (Invitrogen). All data were normalized to GAPDH mRNA levels as an internal control. Primers were as follows: TNF- $\alpha$ : forward: agaagttcccaaatggcctc; reverse: ccacttggtggtttgctacg. IL-6: forward: agttgc cttcttgggactga; reverse: tccacgatttcccagagaac. IL-17: forward: agaagt tcccaaatggcctc; reverse: ccacttggtggtttgctacg; GAPDH: forward: aagatgg tgaaggtcggtg; reverse: gttgatggcaacaatgtccac.

Teff suppression assay. $\mathrm{CD} 4{ }^{+} \mathrm{CD} 25^{+}$Treg and $\mathrm{CD} 4{ }^{+} \mathrm{CD} 25^{-} \mathrm{T}$ effector cells (Teffs) were isolated with the Treg isolation kit as described above. Teffs were stained with CFSE $(1 \mu \mathrm{M})$ for $10 \mathrm{~min}$ in an incubator at $37^{\circ} \mathrm{C}$. After washing, Teffs were transferred to a 96-well plate and cocultured with Tregs at a ratio of 1:1, 2:1, 4:1, 8:1, 16:1, 32:1, or 64:1 in the presence of anti-CD3- and anti-CD28-bounded beads. Suppression of Teff proliferation was determined by CFSE dilution on a flow cytometer $3 \mathrm{~d}$ after coculture.

Experimental design and statistical analysis. Data are expressed as mean \pm SEM. Sample sizes for animal studies were determined by power calculations (SAS) based on pilot studies or the literature (power $80 \%, \alpha$ 0.05). GraphPad Prism software (version 6.0) was used for statistical analyses. The difference in means between two groups was assessed by the Student's $t$ test. Significant differences between means among multiple groups were assessed by one-way ANOVA. Differences in means across multiple groups over time were analyzed using two-way repeatedmeasures ANOVA. When the ANOVA revealed significant differences, the post hoc Bonferroni test was used for pairwise comparisons between means. Detailed information about statistical analysis is included in the Results and summarized in Table 9-1, available at https:// doi.org/10.1523/JNEUROSCI.3411-17.2018.t9-1. $p \leq 0.05$ was considered significant.

\section{Results}

\section{IL-2/IL-2Ab treatment greatly increases the number of Tregs} after tMCAO

We first evaluated the effect of IL-2/IL-2Ab complex on Treg $\left(\mathrm{CD} 4{ }^{+} \mathrm{CD} 25^{+} \mathrm{Foxp}^{+}\right)$abundance in the blood, spleen, and lymph nodes using flow cytometry (Fig. 1A). C57BL/6 mice received IL-2/IL-2Ab (JES6-1) complex ( $1 \mu \mathrm{g}$ of IL-2 plus $5 \mu \mathrm{g}$ of IL-2Ab, i.p.) for $3 \mathrm{~d}$ starting $2 \mathrm{~d}$ before surgery. Control animals received injections of $5 \mu \mathrm{g}$ of isotype IgG (IsoAb) for $3 \mathrm{~d}$. After the last injection, animals were subjected to $60 \mathrm{~min}$ tMCAO or sham operation. Consistent with previous publications (Webster et al., 2009; Koreth et al., 2011; McDonald-Hyman et al., 2016), IL-2/ IL-2Ab treatment robustly induced the Treg number (blood: $t_{(6)}=$ 3.2, $p=0.0186$; spleen: $t_{(9)}=5.618, p=0.0003$; lymph nodes: $t_{(6)}=7.042, p=0.0004$; unpaired $t$ test) and percentage (blood: $t_{(6)}=5.803, p=0.0011$; spleen: $t_{(9)}=9.509, p=0.0001$; lymph nodes: $t_{(6)}=3.805, p=0.0089$; unpaired $t$ test) in sham animals (Fig. $1 B, C$ ). The numbers (blood: $t_{(9)}=3.438, p=0.0074$; spleen: $t_{(10)}=3.539, p=0.0054$; unpaired $t$ test) and percentages (blood: $t_{(9)}=5.417, p=0.0004$; spleen: $t_{(10)}=2.816, p=0.0183$; unpaired $t$ test) of Tregs in $\mathrm{CD} 4{ }^{+}$cells significantly decreased in blood and spleen $3 \mathrm{~d}$ after tMCAO compared with sham controls.
IL-2/IL-2Ab treatment robustly elevated Treg numbers (blood: $t_{(9)}=9.127, p=0.0001$; spleen: $t_{(10)}=5.089, p=0.0005$; lymph nodes: $t_{(6)}=2.803, p=0.031$; unpaired $t$ test) and percentages (blood: $t_{(9)}=9.479, p=0.0001$; spleen: $t_{(10)}=6.37, p=0.0001$; lymph nodes: $t_{(6)}=2.831, p=0.0299$; unpaired $t$ test) in blood, spleen, and lymph nodes (Fig. $1 B, C$ ). Immunohistochemical staining for Foxp 3 confirmed that the number of Foxp ${ }^{+}$Tregs increased in the spleen in IL-2/IL-2Ab-treated stroke mice (Fig. $1 D, t_{(4)}=4.276, p=0.0129$; unpaired $t$ test). We did not observe significant infiltration of Tregs into the brain at 1 or $3 \mathrm{~d}$ after stroke. Tregs were found to infiltrate into brain parenchyma at $5 \mathrm{~d}$ after stroke (Fig. $1 E, 5 \mathrm{~d}: t_{(7)}=13.13, p<0.0001$; unpaired $t$ test). IL-2/IL-2Ab treatment did not result in brain infiltration of Tregs at $3 \mathrm{~d}$ after stroke (Fig. $1 F$ ). These results suggest that Tregs may confer neuroprotection against ischemic brain injury independent of their brain penetration.

The frequencies of other immune cells (Fig. 2A), including $\mathrm{CD}^{-}{ }^{-} \mathrm{B} 220^{+} \mathrm{B}$ cells (blood: $t_{(14)}=0.1343, p=0.8951$; spleen: $t_{(15)}=0.3594, p=0.7243$; unpaired $t$ test $), \mathrm{CD}^{+}{ }^{+} \mathrm{CD} 8{ }^{+} \mathrm{T}$ cells (blood: $t_{(14)}=0.33, p=0.7463$; spleen: $t_{(14)}=0.1514, p=$ 0.8818 ; unpaired $t$ test), CD ${ }^{+} \mathrm{CD} 4{ }^{+}$T cells (blood: $t_{(14)}=1.247$, $p=0.2329$; spleen: $t_{(15)}=1.684, p=0.1129$; unpaired $t$ test $)$, NK $1.1^{+}$NK cells (blood: $t_{(8)}=1.152, p=0.2826$; spleen: $t_{(10)}=$ 2.074, $p=0.0648$; unpaired $t$ test), and $\mathrm{Gr} 1^{+}$neutrophils (blood: $t_{(10)}=0.5648, p=0.5847$; spleen: $t_{(10)}=0.1882, p=0.8545$; unpaired $t$ test), CD $115^{+}$monocytes/macrophages (blood: $t_{(12)}=$ $0.1512, p=0.8823$; spleen: $t_{(11)}=0.1548, p=0.8798$; unpaired $t$ test), were not affected by IL-2/IL-2Ab injection in blood (Fig. $2 B, C$ ) or spleen (Fig. $2 D, E) 3 \mathrm{~d}$ after stroke, suggesting a selective expansion of Tregs by IL-2/IL-2Ab complex. The expression of Ly6C, a phenotypic marker (ElAli and LeBlanc, 2016) of CD $115^{+}$ monocytes, was then assessed. No significant difference was observed in the percentages of $\mathrm{Ly}_{6 \mathrm{C}}{ }^{+} \mathrm{CD} 115^{+}$monocytes/macrophages in IL-2/IL-2Ab-treated mice (blood: $t_{(8)}=0.7619, p=$ 0.4680 ; spleen: $t_{(8)}=0.6348, p=0.5433$; unpaired $t$ test) $3 \mathrm{~d}$ after stroke (Fig. 2C,D), suggesting a minimal effect of IL-2/IL-2Ab on monocytes/macrophages in the periphery early after stroke.

\section{Treatment with IL-2/IL-2Ab complex reduces brain injury and improves sensorimotor functions after stroke}

Next, we investigated whether pre-treatment with IL-2/IL-2Ab protects against ischemic brain injury. TTC staining showed that IL-2/IL-2Ab injection significantly attenuated brain infarct $3 \mathrm{~d}$ after tMCAO (Fig. $3 A, t_{(15)}=3.149, p=0.0066$, unpaired $t$ test). TUNEL staining revealed reduced total cell death TUNEL $^{+}$, $t_{(7)}=4.077, p=0.0047$, unpaired $t$ test) and reduced number of dead/dying neurons $\left(\mathrm{TUNEL}^{+} \mathrm{NeuN}^{+}, t_{(7)}=3.793, p=0.0068\right.$, unpaired $t$ test) in peri-infarct areas in IL-2/IL-2Ab-treated stroke mice compared with IsoAb-treated controls (Fig. 3B). Tregs inhibit inflammatory responses after stroke (Liesz et al., 2009; Li et al., 2013). We therefore measured the expression of several inflammatory cytokines that are known to exacerbate stroke outcomes in IsoAb- and IL-2/IL-2Ab-treated stroke mice. IL-2/IL-2Ab markedly inhibited the otherwise elevated inflammatory cytokines, including IL-6 $\left(F_{(2,14)}=8.083, p=0.0046\right.$; sham vs IsoAb, $p=0.0348$; IsoAb vs IL-2/IL-2Ab, $p=0.0055$; one-way ANOVA followed by Bonferroni post hoc), TNF$\alpha\left(F_{(2,14)}=13.32, p=0.0006\right.$; sham vs IsoAb, $p=0.0003$; IsoAb vs IL-2/IL-2Ab, $p=0.0356$; one-way ANOVA followed by Bonferroni post hoc) and IL-17 $\left(F_{(2,14)}=5.604, p=0.0163\right.$; sham vs IsoAb, $p=0.0368$; IsoAb vs IL-2/IL-2Ab, $p=0.0173$; one-way ANOVA followed by Bonferroni post hoc) in ischemic brain (Fig. $3 C)$. Consistent with reduced inflammation, the infiltration of 
A
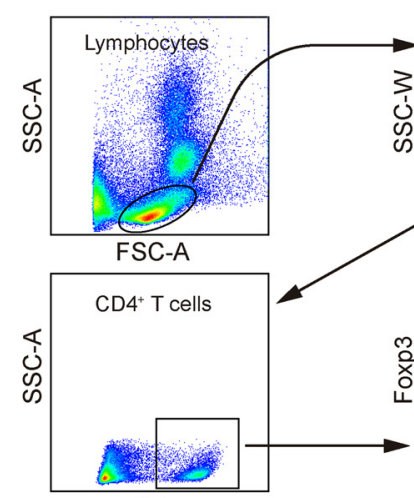

CD4

C
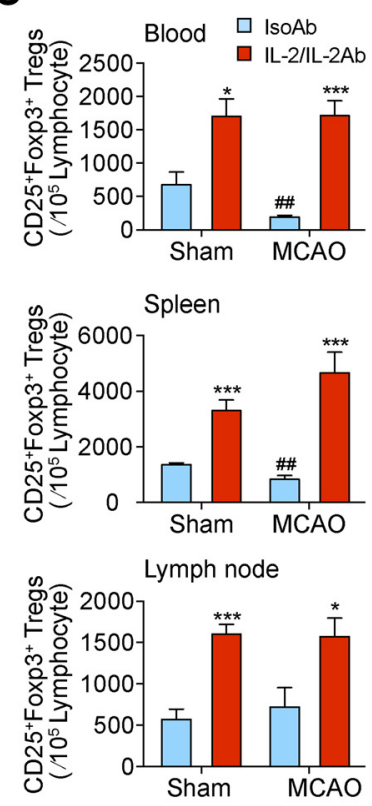

E

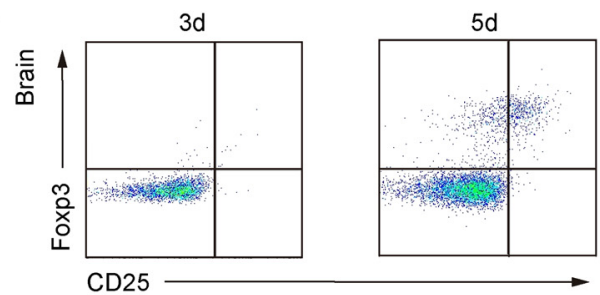

B
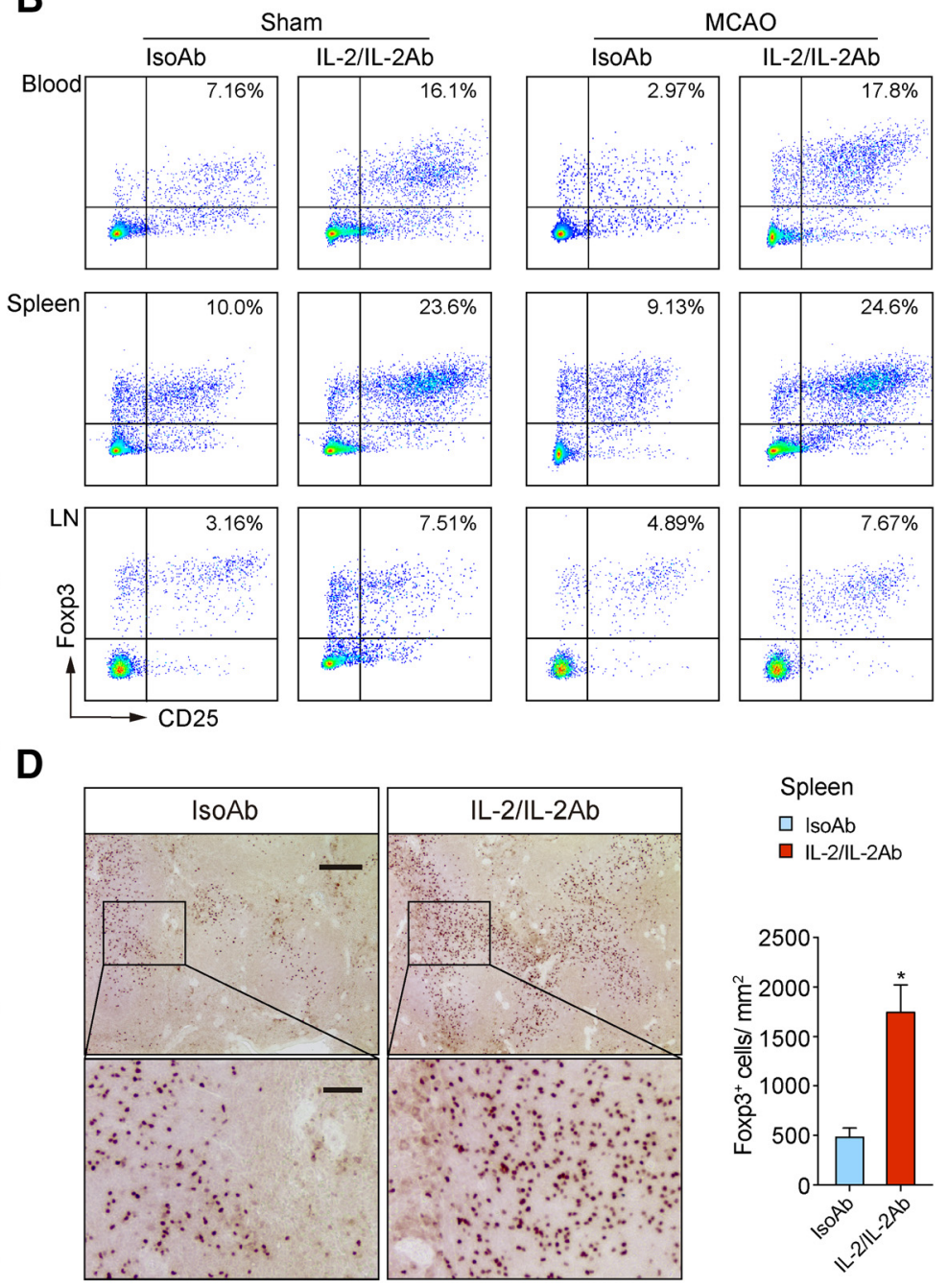

Spleen

$\square$ IsoAb

प IL-2/L-2Ab

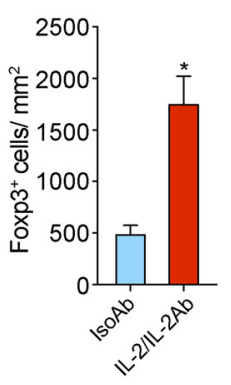

F

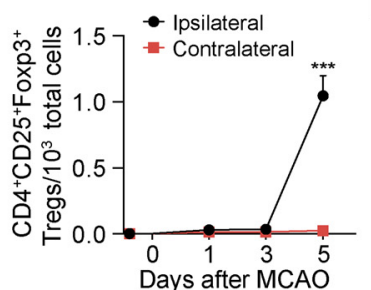

F

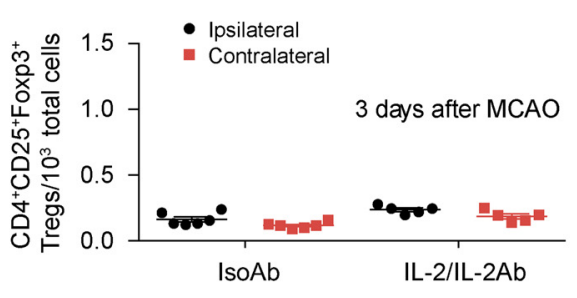

Figure 1. IL-2/L-2Ab treatment greatly expands the Treg population. $A-C$, C57BL/ 6 mice were treated with IL-2/L-2Ab complex or IsoAb intraperitoneally for $3 \mathrm{~d}$ before $60 \mathrm{~min} \mathrm{MCA0}$ or sham operation. Blood, spleen, and lymph node (LN) cells were analyzed for the expression of CD4, CD25, and Foxp3 by flow cytometry. $\boldsymbol{A}$, Gating strategy for $\mathrm{CD} 4{ }^{+} \mathrm{CD} 25^{+}$Foxp $3{ }^{+}$Tregs. $\boldsymbol{B}$, Representative flow cytometry plots of $\mathrm{CD} 4{ }^{+} \mathrm{CD} 25^{+}$Foxp $3^{+}$Tregs derived from the blood, spleen, and LN of sham (left) or MCA0 (right) mice. C, Percentages of CD25 ${ }^{+}$Foxp $3^{+}$Tregs among $\mathrm{CD4}{ }^{+} \mathrm{T}$ cells in blood, spleen, and LNs and the number of $\mathrm{CD} 4{ }^{+} \mathrm{CD} 25^{+} \mathrm{Foxp}^{+}{ }^{+}$Tregs in $10^{5}$ lymphocytes in blood, spleen, and LNs significantly increased in IL-2/LL-2Ab-treated group compared with IsoAb-treated group $3 \mathrm{~d}$ after MCA0 or sham operation. $n=4-7 /$ group. ${ }^{*} p<0.05,{ }^{* *} p<0.01$, ${ }^{* * *} p<0.001$, IL-2/IL-2Ab versus IsoAb; \#p $<0.05$, \#\#p $<0.01$, \#\#\#p $<0.001$, IsoAb MCA0 versus IsoAb sham. $\boldsymbol{D}$, Immunostaining (left) and quantification (right) of Foxp ${ }^{+}$cells in the spleen demonstrating increased Treg number after IL-2/IL-2Ab treatment. $n=3 / \mathrm{group} . \mathrm{Scale}$ bar, top, $200 \mu \mathrm{m}$; bottom, $50 \mu \mathrm{m} . \mathrm{E}_{,} \mathrm{CD}^{+}{ }^{+} \mathrm{CD} 25^{+} \mathrm{FoxP3}{ }^{+}$Treg infiltration into the ischemic brain was detected by flow cytometry at the indicated time points after $60 \mathrm{~min}$ tMCA0. $n=3-5 / \mathrm{group} .{ }^{* * *} p<$ 0.001 ipsilateral versus contralateral at the indicated time point after tMCA0. $F$, No significant infiltration of Tregs was detected in the ischemic brain $3 \mathrm{~d}$ after stroke in either IsoAb or IL-2/IL-2Abtreated mice. $n=5-6 /$ group.

$\mathrm{CD}^{+} \mathrm{T}$ cells to the ischemic brain significantly decreased (Fig. $3 D$, striatum: $t_{(9)}=3.415, p=0.0077$; cortex: $t_{(9)}=3.892, p=$ 0.0037; unpaired $t$ test) in IL-2/IL-2Ab-treated stroke mice. The number of $\mathrm{F} 4 / 80^{+}$monocyte/macrophages and microglia in striatum also was reduced (Fig. $3 D$, striatum: $t_{(12)}=2.192, p=$ 0.0446 ; cortex: $t_{(12)}=1.853, p=0.0887$; unpaired $t$ test) in IL-2/ IL-2Ab-treated stroke mice. FACS (Fig. 3E) confirmed that the number of $\mathrm{CD} 45^{\text {high }} \mathrm{CD} 11 \mathrm{~b}^{+}$macrophages $\left(t_{(8)}=2.579, p=\right.$
0.0327, unpaired $t$ test) was reduced in the ischemic brain in IL-2/IL-2Ab-treated stroke mice (Fig. 3F, H). IL-2/IL-Ab treatment did not change the number of $\mathrm{CD} 45^{\text {intermediate }} \mathrm{CD} 11 \mathrm{~b}^{+} \mathrm{mi}-$ croglia $\left(t_{(8)}=1.26, p=0.2430\right.$, unpaired $t$ test $)$ in the ischemic area (Fig. $3 F, G$ ). The IL-2/IL-2Ab-afforded protection lasted until at least $7 \mathrm{~d}$ after stroke, as revealed by reduced tissue loss in MAP2-stained brain slices (Fig. 3I, $t_{(16)}=2.889, p=0.0107$, unpaired $t$ test). 
A

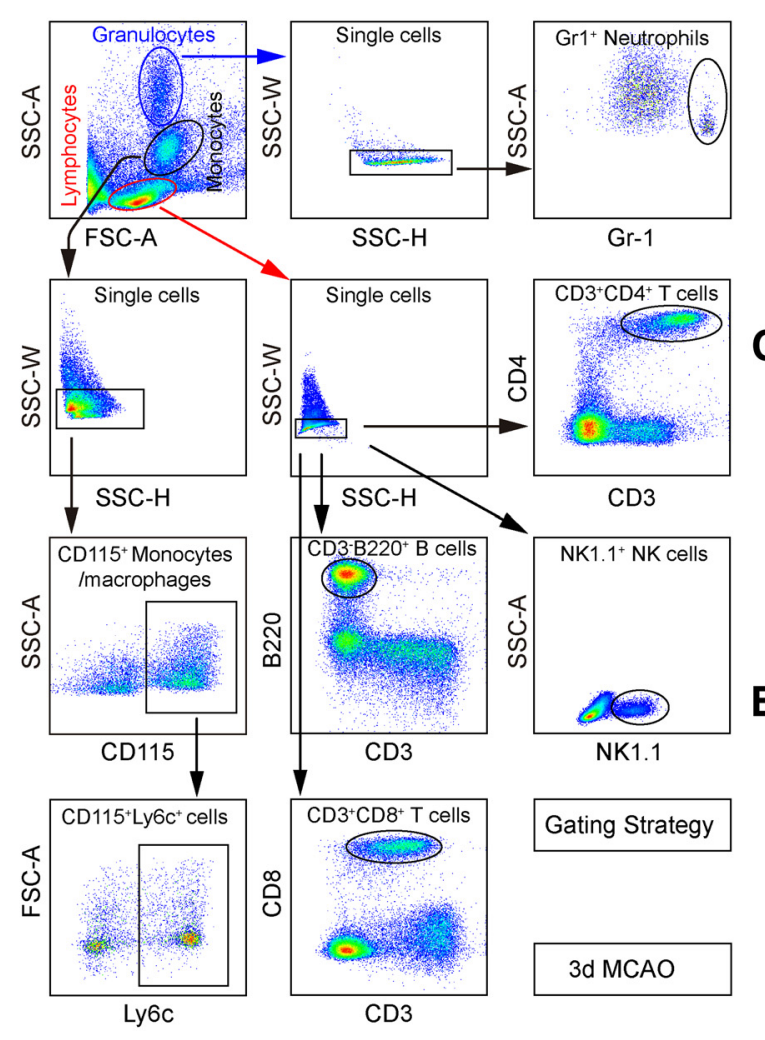

B

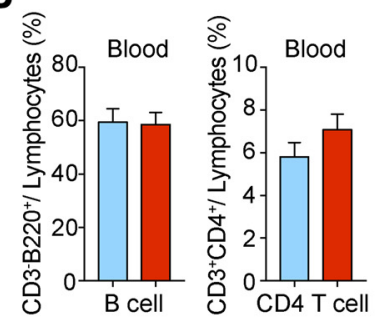

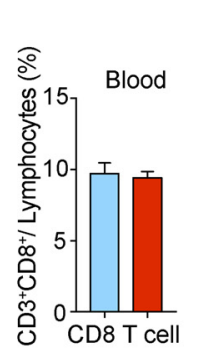

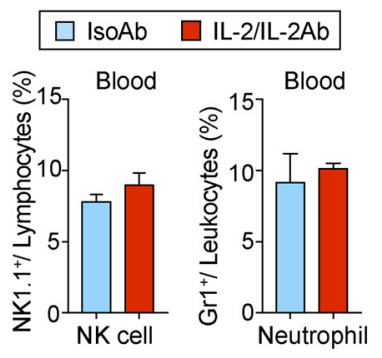

C

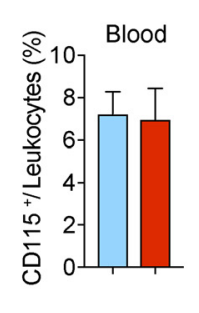

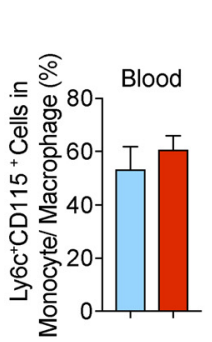

D

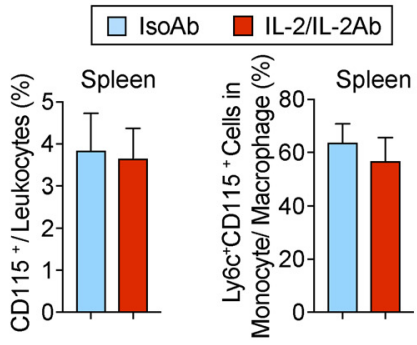

E
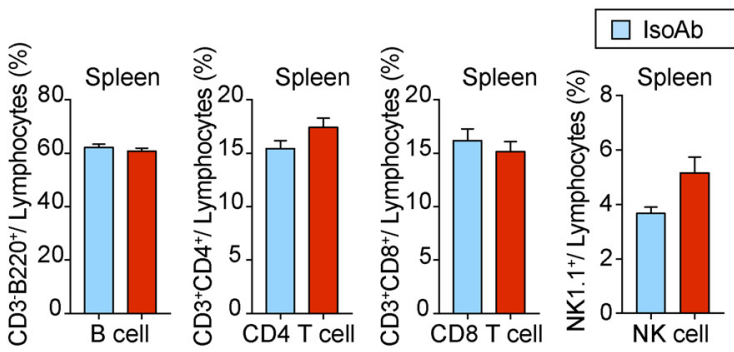

IL-2/IL-2Ab

Figure 2. IL-2/IL-2Ab treatment has little influence on non-Treg populations. $\boldsymbol{A}$, Gating strategy for $\mathrm{CD} 3^{-} \mathrm{B} 22 \mathrm{O}^{+} \mathrm{B}$ cells, $\mathrm{CD} 3^{+} \mathrm{CD} 4{ }^{+} \mathrm{T}$ cells, $\mathrm{CD} 3{ }^{+} \mathrm{CD} 8{ }^{+} \mathrm{T}$ cells, NK1.1 ${ }^{+} \mathrm{NK}$ cells, Gr1 ${ }^{+}$ neutrophils, and CD115 ${ }^{+}$monocytes. $\boldsymbol{B}-\boldsymbol{E}$, Percentages of peripheral B cells, CD4 ${ }^{+}$T cells, CD8 ${ }^{+}$T cells, NK cells, neutrophils, and monocytes in blood (B, $\boldsymbol{C}$ and spleen ( $\left.\boldsymbol{D}, \boldsymbol{E}\right)$ showed no change after IL-2/IL-2Ab treatment. $n=5-9 /$ group.

To further evaluate the therapeutic potential of IL-2/IL-2Ab, we injected the complex $2 \mathrm{~h}$ after stroke and repeated once per day for the following $2 \mathrm{~d}$. The IL-2/IL-2Ab posttreatment reduced brain infarct $7 \mathrm{~d}$ after tMCAO (Fig. $4 A, t_{(17)}=3.636, p=0.002$, unpaired $t$ test). The sensorimotor functions, as measured by rotarod test $\left(F_{(1,15)}=6.032, p=0.0267 ; 2\right.$-way ANOVA repeated measurement), and foot fault test $\left(F_{(1,14)}=25.83, p=0.0002\right.$; 2-way repeated-measures ANOVA) (Fig. 4B), were improved in IL-2/IL-2Ab-treated mice compared with IsoAb-treated mice after stroke.

\section{Tregs are essential for IL-2/IL-2Ab complex-afforded neuroprotection}

To confirm whether IL-2/IL-2Ab complex-provided protection against ischemic stroke was indeed mediated through Treg expansion, we selectively depleted Tregs by DT injection into DTR transgenic mice that express DT receptor under the control of Foxp3 promoter. Mice received DT or the same volume of PBS before IL-2/IL-2Ab or IsoAb treatment. Efficacy of depletion was evaluated by flow cytometry. Approximately $90 \%$ of $\mathrm{CD} 4{ }^{+}$ $\mathrm{CD} 25^{+}$Foxp $3^{+}$Tregs were depleted in both blood and spleen and the IL-2/IL-2Ab complex failed to stimulate a growth in Treg population (Fig. $5 A, B$ ), suggesting efficient depletion of Tregs in DT-treated DTR mice. Consistent with previous studies (Liesz et al., 2009; Ren et al., 2011; Li et al., 2013), depletion of endogenous Tregs did not change the size of infarct $3 \mathrm{~d}$ after tMCAO. IL-2/IL-2Ab treatment reduced infarct volume in DTR mice without DT injection; however, this protection was abolished when DT was injected (Fig. $5 C, D, F_{(3,25)}=5.039$, $p=0.0072$; DTR-DT IsoAb vs DTR-DT IL-2/IL-2Ab, $p=$ 0.0280; one-way ANOVA followed by Bonferroni post hoc). In summary, these results indicate a crucial role of Tregs in IL-2/ $\mathrm{IL}-2 \mathrm{Ab}$ complex-induced neuroprotection against ischemic stroke.

\section{IL-2/IL-2Ab complex enhances the protective functions of expanded Tregs}

To determine whether IL-2/IL-2Ab only increases the number of Tregs or also enhances their functions, equal numbers $\left(1 \times 10^{6}\right)$ of Tregs were isolated from isotype-treated or IL-2/IL-2Abtreated mice and transferred into stroke mice $2 \mathrm{~h}$ after tMCAO (Fig. 6A). Consistent with our previous study (Li et al., 2013), adoptive transfer of $1 \times 10^{6}$ Tregs (which was lower than the therapeutic dose of $2 \times 10^{6} /$ mouse) prepared from IsoAbtreated mice slightly, but not significantly, reduced infarct volume compared with PBS-treated stroke mice. Interestingly, an equal number of Tregs isolated from IL-2/IL-2Ab-treated mice resulted in a significant attenuation of brain infarct compared with PBS- and IsoAb-treated Tregs (Fig. $6 B, C, F_{(2,24)}=6.812$, $p=0.0045 ;$ PBS vs IL-2/IL-2Ab Treg, $p=0.0052$; IsoAb Treg vs IL-2/IL-2Ab Treg, $p=0.0367$; one-way ANOVA followed by Bonferroni post hoc). These results suggest that IL-2/IL-2Ab complex not only expands the number of Tregs, but also enhances the functions of Tregs. In vitro studies confirmed that Tregs isolated from IL-2/IL-2Ab-treated mice have stronger capacities to inhibit the proliferation of Teffs compared with Tregs isolated from IsoAb-treated mice (Fig. 6D). 
A

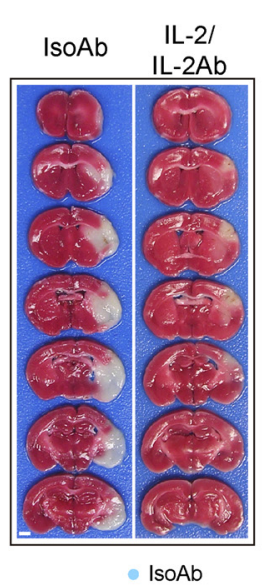

$\left.{ }^{2} \quad 100\right]=\mathrm{IL}-2 / \mathrm{LL}-2 \mathrm{Ab}$

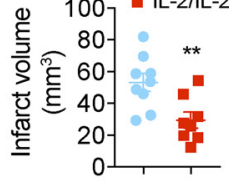

B

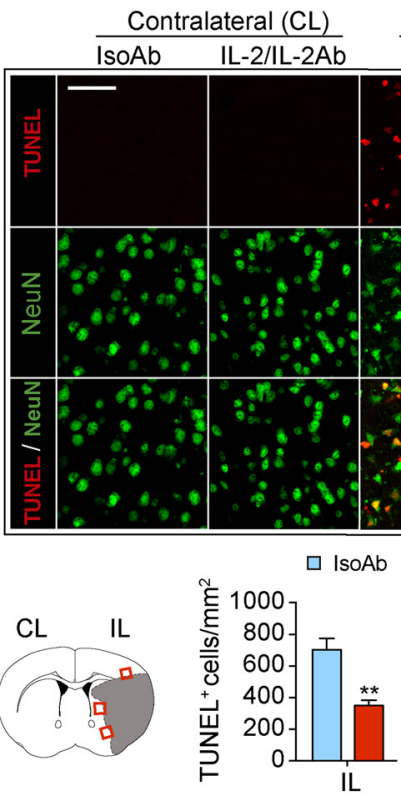

Ipsilateral (IL) IL-2/IL-2Ab
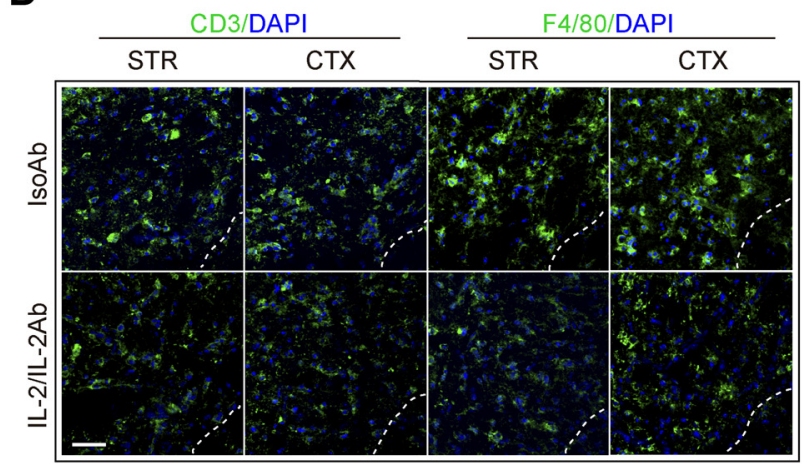

$\square$ ISOAb

口 IL-2/IL-2Ab

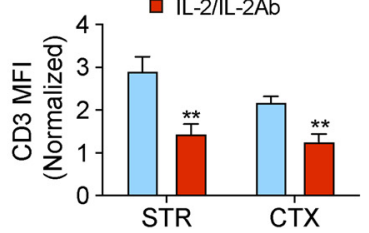

IsoAb

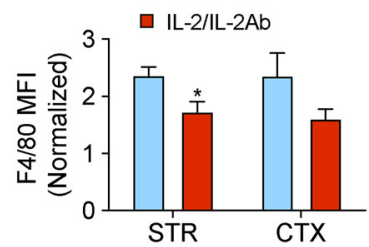

E
C
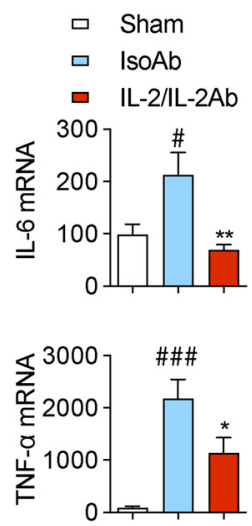

$\square \mathrm{IL}-2 / \mathrm{IL}-2 \mathrm{Ab}$
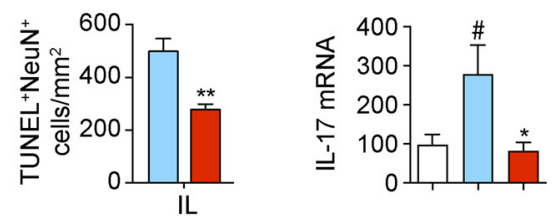

I
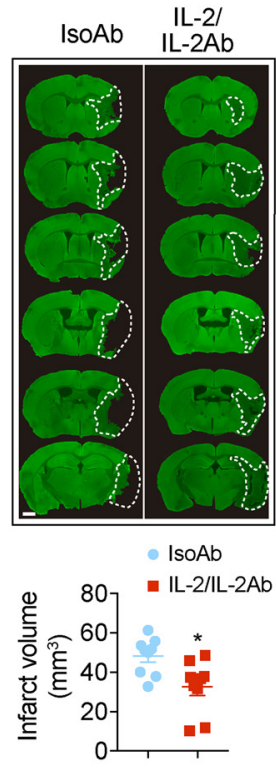

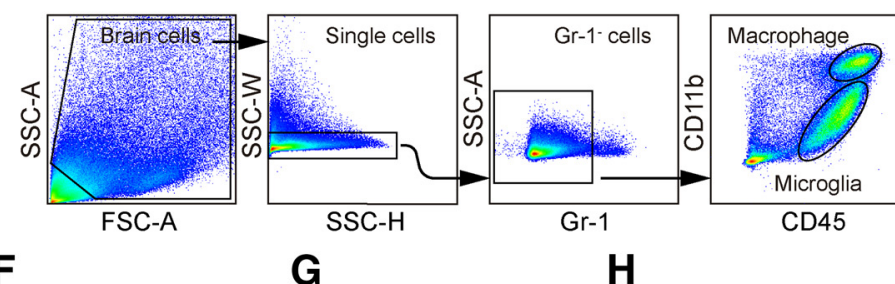

Microglia

Macrophage

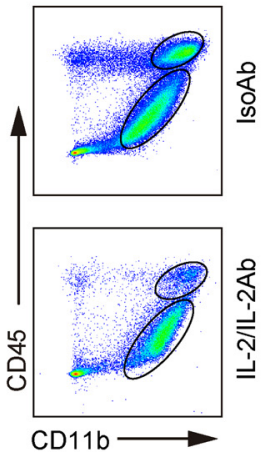

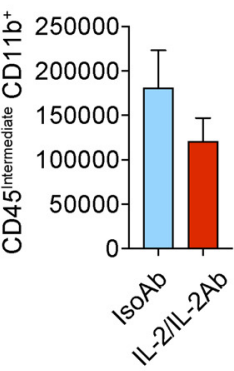

Figure 3. IL-2/LL-2Ab treatment reduces ischemic brain injury. C57BL/6 mice were pretreated with IL-2/IL-2Ab complex or IsoAb intraperitoneally for $3 \mathrm{~d}$ before tMCA0. $A$, Quantification of TTC staining for brain infarct $3 \mathrm{~d}$ after ischemic stroke. $n=8-9 /$ group. Scale bar, $1 \mathrm{~mm}$. B, Quantification of cell death (TUNEL ${ }^{+}$) and neuronal death (TUNEL ${ }^{+} \mathrm{NeuN}^{+}$) in peri-infarct areas $($shown in the schematic) $3 \mathrm{~d}$ after tMCA0. $n=4-5 /$ group. Scale bar, $100 \mu \mathrm{m}$. C, mRNA expression of IL-6, TNF- $\alpha$, and IL-17 in sham and ischemic brains was quantified using RT-PCR $3 \mathrm{~d}$ after tMCA0. $n=$ 5-6/group. D, Top, Representative images of CD3 (green)/DAPI (blue) T cells and F4/80 (green)/DAPI (blue) monocyte/macrophages and microglia in striatum and cortex in the peri-infarct areas. Scale bar, $100 \mu \mathrm{m}$. Bottom, Quantification of the mean fluorescent intensity (MFI) for CD3 ${ }^{+}$staining ( $n=5-6 /$ group) and F4/80 ${ }^{+}$staining $(n=6-8 /$ group). Data are normalized to the contralateral levels. $\boldsymbol{E}-\boldsymbol{H}$, Flow cytometric analysis of $\mathrm{CD} 45^{\text {high }} \mathrm{CD} 11 \mathrm{~b}{ }^{+}$macrophages and $\mathrm{CD} 45^{\text {intermediate }} \mathrm{CD} 11 \mathrm{~b}{ }^{+}$microglia in the ischemic brain. $\boldsymbol{E}$, Gating strategy. $\boldsymbol{F}$, Representative $F A C S$ plots for microglia and macrophages in the brains of IsoAb or IL-2/IL-2Ab-treated stroke mice. $\mathbf{G}, \boldsymbol{H}$, Quantification of the numbers of $C D 45^{\text {intermediate }}$ CD11b ${ }^{+}$microglia $(\boldsymbol{G})$ and $C D 45^{\text {high }} \mathrm{CD} 11 \mathrm{~b}{ }^{+}$ macrophages $(\boldsymbol{H})$ per ischemic brain of IsoAb or IL-2/L-2Ab-treated stroke mice. $n=5 / \mathrm{group}$. $\boldsymbol{I}$, Infarct volume was measured by MAP2 immunostaining $7 \mathrm{~d}$ after tMCA0. $n=9 / \mathrm{group}$. Scale bar, $1 \mathrm{~mm} .{ }^{*} p<0.05,{ }^{* *} p<0.01$ versus IsoAb; \#p $<0.05$, \#\#p $<0.001$ versus sham.

\section{IL-2/IL-2Ab complex enhances CD39/CD73 signaling} in Tregs

We also sought to elucidate the mechanism for IL-2/IL-2Abinduced functional change in Tregs. CD39 and CD73 are expressed on activated Foxp $3^{+}$Tregs (Sakaguchi et al., 2010). The CD39/CD73 axis catalyzes the conversion of ATP to ADP and AMP, which is followed by the generation of adenosine that mediates the immunosuppressive and anti-inflammatory functions of Tregs (Antonioli et al., 2013). We therefore investigated whether the enhancement of Treg function by the IL-2/IL-2Ab complex is related to an elevation of CD39/CD73 expression on
Tregs. CD39 and CD73 were expressed on $\mathrm{CD} 4{ }^{+} \mathrm{CD} 25^{+} \mathrm{Foxp} 3^{+}$ Tregs in blood, spleen, and lymph nodes in the IsoAb-treated group $3 \mathrm{~d}$ after tMCAO (Fig. $7 A-D$ ). With IL-2/IL-2Ab treatment, the percentages of CD $39^{+}$Tregs (Fig. $7 B, C$, blood: $t_{(12)}=$ $5.563, p=0.0001$; spleen: $t_{(11)}=6.548, p=0.0001$; lymph nodes: $t_{(6)}=1.999, p=0.0925$; unpaired $t$ test) and CD73 ${ }^{+}$Tregs (Fig. $7 B, C$, blood: $t_{(12)}=3.491, p=0.013$; spleen: $t_{(11)}=7.76, p=$ 0.0001 ; lymph nodes: $t_{(6)}=2.271, p=0.0636$; unpaired $t$ test) were increased. The absolute numbers of $\mathrm{CD} 39^{+}$Tregs (Fig. $7 D$, blood: $t_{(12)}=5.012, p=0.0003$; spleen: $t_{(11)}=4.436, p=0.0008$; lymph nodes: $t_{(6)}=4.513, p=0.004$; unpaired $t$ test) and CD73 ${ }^{+}$ 
A

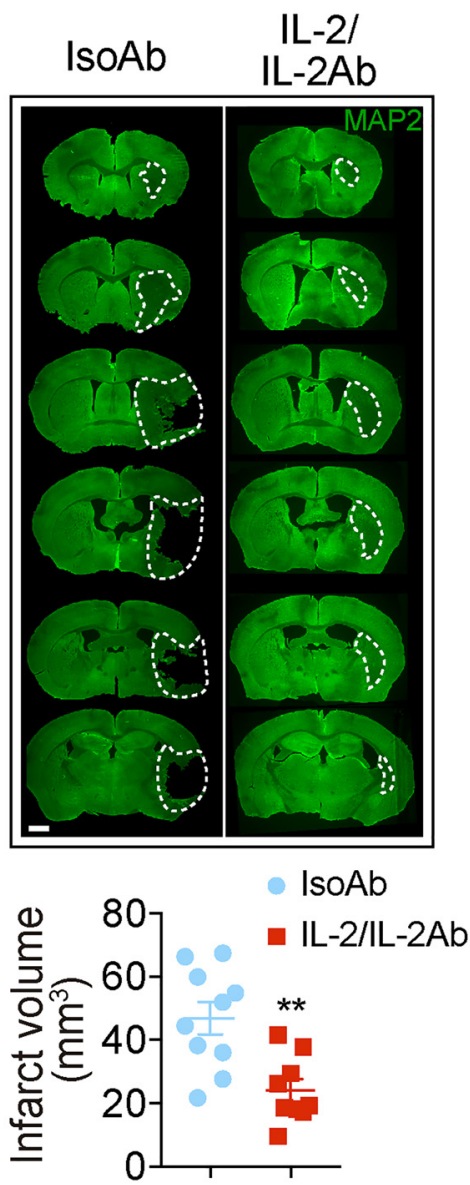

B
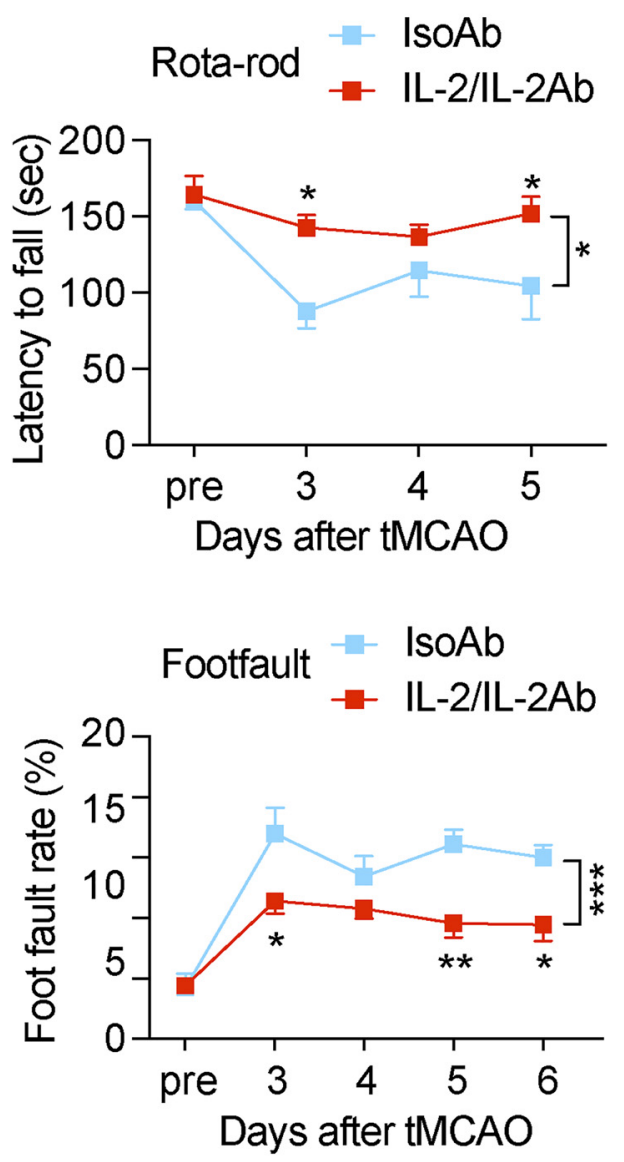

Figure 4. IL-2//L-2Ab poststroke treatment reduces ischemic brain injury and improves sensorimotor functions after tMCA0. C57BL/6 mice were posttreated with IL-2/LL-2Ab complex or IsoAb intraperitoneally for $3 \mathrm{~d}$ starting from $2 \mathrm{~h}$ after $\mathrm{MCA}$. $A$, Infarct volume was measured by MAP 2 immunostaining $7 \mathrm{~d}$ after $\mathrm{TMCA0} . n=9-10 /$ group. Scale bar, $1 \mathrm{~mm}$. $\boldsymbol{B}$, Sensorimotor functions were accessed by rotarod test and foot fault test after stroke. $n=6-9 /$ group. ${ }^{*} p<0.05,{ }^{* *} p<0.01,{ }^{* * *} p<0.001$.

A
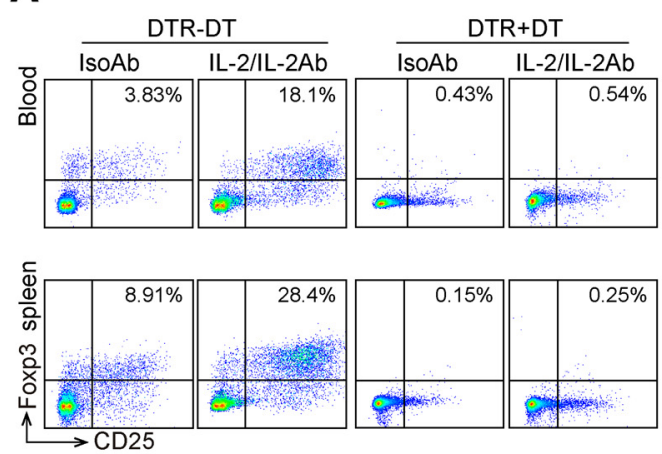

B

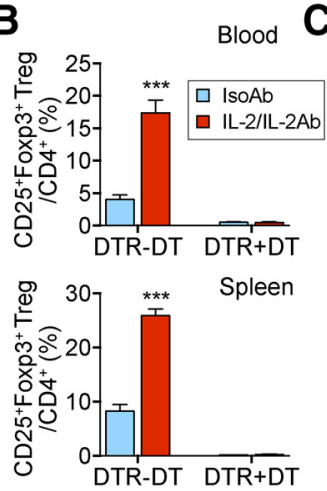

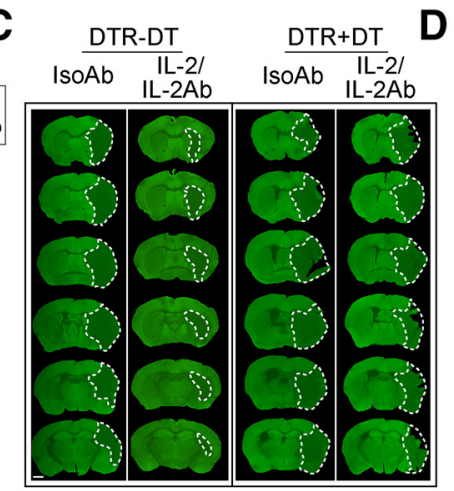

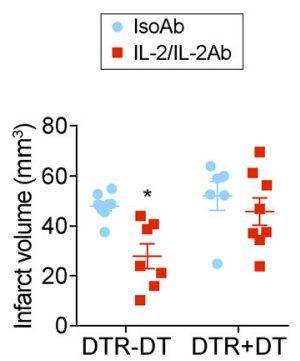

Figure 5. Tregs are essential for IL-2/IL-2Ab-afforded neuroprotection against ischemic stroke. DTR mice were injected with DT intraperitoneally for $3 d$ to deplete Tregs. Control DTR mice received the same amount of PBS. IL-2/IL-2Ab complex or IsoAb was intraperitoneally injected after DT for $3 \mathrm{~d}$ before tMCA0. Animals were killed $3 \mathrm{~d}$ after tMCA0. $A, B$, Blood and spleen cells were stained with CD4, CD25, and Foxp3 antibodies to evaluate the Treg population. $\boldsymbol{A}$, Representative flow cytometry plots of $\mathrm{CD}_{25}{ }^{+}$Foxp3 ${ }^{+}$Tregs among $C D 4^{+} \mathrm{T}$ cells. $\boldsymbol{B}$, Percentages of $\mathrm{CD}_{25}{ }^{+}$Foxp $3^{+}$Tregs among $\mathrm{CD} 4{ }^{+}$T cells in blood (top) and spleen (bottom). $n=6-7 /$ group. $C, \boldsymbol{D}$, Brain slices were stained with MAP2 for infarct volume measurement. $\boldsymbol{C}$, Representative images of MAP2 staining for DTR mice without DT treatment (DTR-DT) or DTR mice with DT treatment (DTR+DT) $3 \mathrm{~d}$ after tMCAO. Scale bar, $1 \mathrm{~mm}$. D, Quantification of MAP2 staining showing that IL-2/IL-2Ab treatment decreased brain infarct in DTR -DT mice, whereas the protection effect was abolished in DTR+DT mice. $n=6-8 /$ group. ${ }^{*} p<0.05$, ${ }^{* * *} p<0.001 \mathrm{IL}-2 / \mathrm{LL}-2 \mathrm{Ab}$ versus IsoAb in DTR-DT mice.

Tregs (Fig. 7D, blood: $t_{(12)}=4.177, p=0.0013$; spleen: $t_{(11)}=$ $3.745, p=0.0027$; lymph nodes: $t_{(6)}=2, p=0.0407$; unpaired $t$ test) were also significantly increased in the IL-2/IL-2Ab group compared with the IsoAb group.

We then conducted an in vitro experiment to confirm the effect of IL-2/IL-2Ab complex on CD39 and CD73 expression on
Tregs. Splenocytes were isolated and treated with IsoAb, IL-2, or IL-2/IL-2Ab for $3 \mathrm{~d}$. Consistent with in vivo data, the numbers of CD39 ${ }^{+}$Tregs (Fig. $7 E, F_{(3,12)}=45.44, p=0.0001$; Non vs IL-2, $p=0.0029$; non- vs IL-2/IL-2Ab, $p=0.0001$; IsoAb vs IL- $2, p=$ 0.0045 ; IsoAb vs IL-2/IL-2Ab, $p=0.0001$; one-way ANOVA followed by Bonferroni post hoc) and $\mathrm{CD}^{+} 3^{+}$Tregs (Fig. 7F, 
A

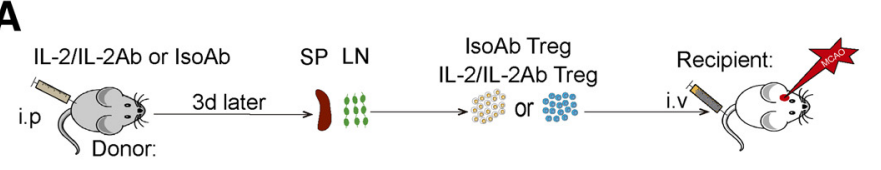

B

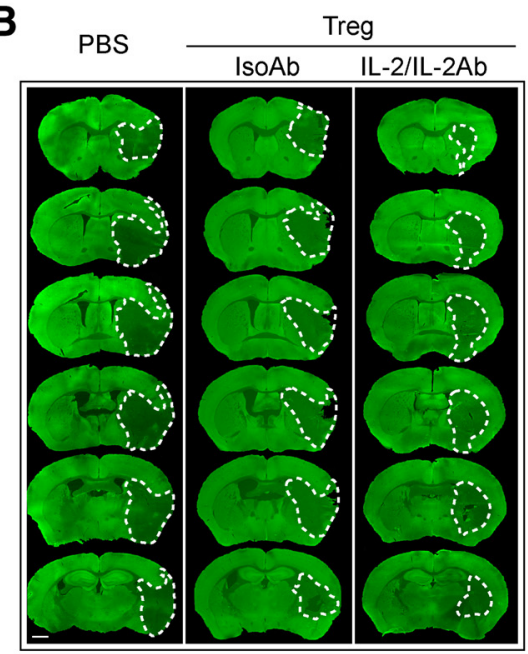

C

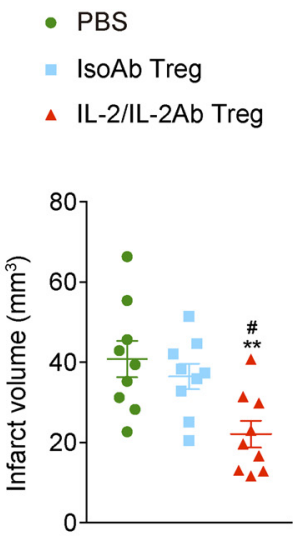

D
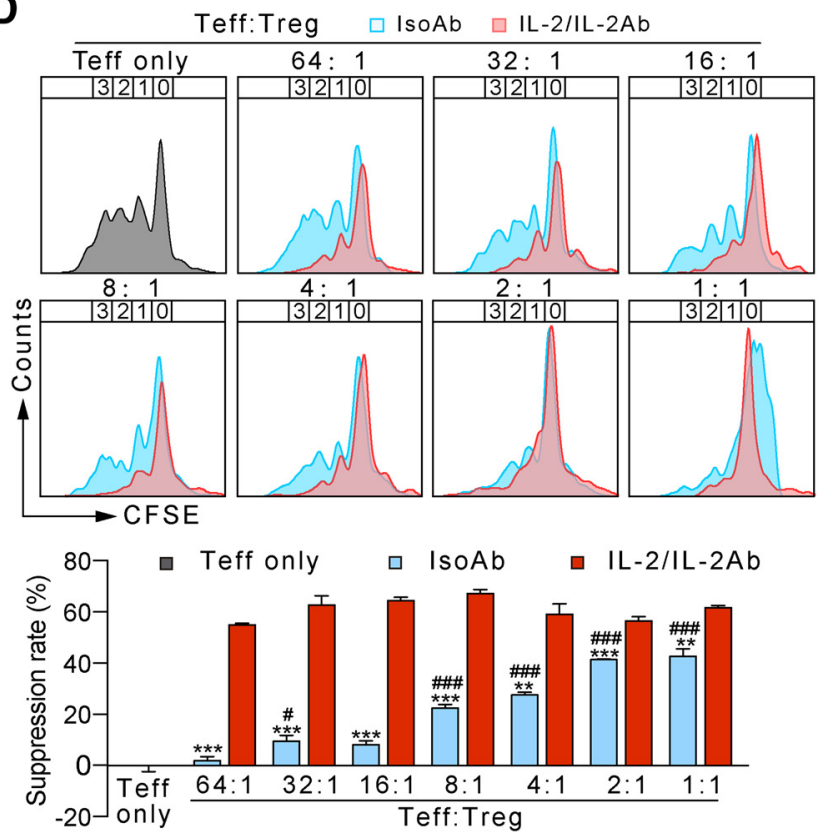

Figure 6. IL-2//L-2Ab enhances the protective effect of Tregs. Tregs were isolated from donor C57BL/6 mice that were pretreated with IL-2/IL-2Ab (IL-2/IL-2Ab Tregs) or IsoAb (IsoAb Tregs) for $3 \mathrm{~d}$. A total of $1 \times 10^{6} \mathrm{IsOAb}$ Tregs or IL-2/LL-2Ab Tregs was transferred into recipient C57BL/ 6 mice through tail vein $2 \mathrm{~h}$ after tMCA0. Control mice received the same volume of PBS. Animals were killed $3 \mathrm{~d}$ after tMCAO. A, Schematic images for experimental design. $B$, Representative images of MAP2 staining. Scale bar, $1 \mathrm{~mm}$. C, Quantification of infarct volume. $n=9 / \mathrm{group} .{ }^{* *} p<0.01$ IL-2/LL-2Ab Treg versus PBS. \#p $<0.05 \mathrm{IL}-2 / \mathrm{IL}-2 \mathrm{Ab}$ Tregs versus IsoAb Tregs. D, Suppressive function of IL-2/LL-2Ab or IsoAb-treated Tregs. Teffs were labeled with CFSE (1 $\left.\mu \mathrm{M}, 37^{\circ} \mathrm{C}, 10 \mathrm{~min}\right)$. Tregs prepared from IL-2/LL-2Ab or IsoAb-treated mice were added at a ratio of 1:1, 1:2, 1:4, 1:8, 1:16, 1:32, or 1:64 to the number of Teffs. Cells were incubated for $3 \mathrm{~d}$. Suppression of Teff proliferation was determined by CFSE dilution on a flow cytometer. Top, Representative plots of suppression assay using CFSE-labeled Teffs incubated with Tregs at various ratios. Bottom, Bar graph indicating CFSE dilution in CD4 ${ }^{+}$CD25- gated Teffs. The percentage of suppression was calculated as $100-(\%$ divided with Tregs $/ \%$ divided without Tregs $) \times 100$. Data are shown as mean \pm SEM of three independent experiments. ${ }^{* *} p<0.01,{ }^{* * *} p<0.001$ versus IsoAb, unpaired $t$ test; $\# p<0.05$, \#\#\#p $<0.001$ versus Teff alone, one-way ANOVA followed by Bonferroni post hoc.

$F_{(3,12)}=50.22, p=0.0001$; non- vs IL-2, $p=0.0012$; non- vs IL-2/IL-2Ab, $p=0.0001$; IsoAb vs IL- $2, p=0.0038$; IsoAb vs IL-2/IL-2Ab, $p=0.0001$; one-way ANOVA followed by Bonferroni post hoc) were expanded in both IL-2- and IL-2/IL$2 \mathrm{Ab}$-treated groups compared with no treatment control or IsoAb-treated groups. Importantly, IL-2/IL-2Ab treatment significantly increased the numbers of $\mathrm{CD}^{+} 9^{+}$Tregs $\left(F_{(3,12)}=\right.$ 45.44, $p=0.0001$; IL-2 vs IL-2/IL-2Ab, $p=0.0009$; one-way ANOVA followed by Bonferroni post hoc) and $\mathrm{CD}^{+}{ }^{+}$Tregs $\left(F_{(3,12)}=50.22, p=0.0001\right.$; IL-2 vs IL-2/IL-2Ab, $p=0.0007$; one-way ANOVA followed by Bonferroni post hoc) compared with IL-2 alone. In summary, these data suggest that IL-2/IL-2Ab treatment not only expands the number of Tregs, but also enhances the expression of CD39 and CD73 on Tregs.

\section{CD73 deficiency reduces the protective effect of adoptively transferred Tregs}

To confirm that CD39/CD73 signaling in Tregs is important for IL-2/IL-2Ab-afforded protection against stroke, we injected IL$2 / \mathrm{IL}-2 \mathrm{Ab}$ or IsoAb into CD73 KO mice. Although IL-2/IL-2Ab was able to expand the number (Fig. $8 D$, blood: $t_{(4)}=10.08, p=$ 0.0005 , unpaired $t$ test; spleen: $t_{(4)}=5.046, p=0.0073$, unpaired $t$ test) and percentage (Fig. $8 C, E$, blood: $t_{(4)}=13.48, p=0.0002$, unpaired $t$ test; spleen: $t_{(4)}=5.121, p=0.0069$, unpaired $t$ test) of Tregs in CD73 KO mice, it failed to protect the brain against tMCAO (Fig. $8 A, B, t_{(14)}=0.8008, p=0.4367$, unpaired $t$ test). We then compared the effect of $\mathrm{CD} 4{ }^{+} \mathrm{CD} 25^{+}$Tregs isolated from IsoAb-treated or IL-2/IL-2Ab-treated WT or CD73 KO mice. Four types of Tregs were prepared in this experiment: (1) IsoAb-treated WT (WT-IsoAb), (2) IL-2/IL-2Ab-treated WT (WT-IL-2/IL-2Ab), (3) IsoAb-treated CD73KO (KO-IsoAb), and (4) IL-2/IL-2Ab-treated CD73KO (KO-IL-2/IL-2Ab). WT recipient mice treated with WT-IL-2/IL-2Ab Tregs showed a significant attenuated infarct volume compared with WT-IsoAb Tregs-treated stroke mice, whereas Tregs prepared from CD73 KO mice failed to show protection (Fig. $8 F, F_{(3,24)}=8.032, p=$ 0.0007; WT-IsoAb Treg vs WT-IL-2/IL-2Ab Treg: $p=0.0215$; WT-IL-2/IL-2Ab Treg vs KO-IL-2/IL-2Ab Treg: $p=0.0011$; KOIsoAb Treg vs KO-IL-2/IL-2Ab Treg: $p>0.9999$, one-way ANOVA followed by Bonferroni post hoc). Together, these data suggest that CD73 expression on Tregs plays a crucial role in IL-2/IL-2Ab-afforded protection.

\section{Discussion}

This study investigated the protective effect of IL-2/IL-2Ab against ischemic stroke. Our data demonstrated that IL-2/IL-2Ab significantly reduced brain infarction and improved neurological functions after stroke. We further identified that IL-2/IL-2Ab not only expanded the number of Tregs, but also promoted their functions and enhanced the expression of CD39/CD73.

Selective Treg expansion with IL-2/IL-2Ab was initially reported by Boyman et al. (2006). Specifically, the JES6-1 IL-2 $\mathrm{mAb}$ in the complex blocks the CD122-binding epitope (for $\mathrm{CD}^{+}{ }^{+} \mathrm{T}$-cell and NK cell recognition) on IL-2 and therefore endorses the specificity of this complex for Treg stimulation. Accumulating studies have confirmed that the IL-2/IL-2Ab (JES6-1) complex expands the number of Tregs without causing significant changes in total CD $4{ }^{+} \mathrm{T}_{\text {cells, }} \mathrm{CD} 8^{+} \mathrm{T}$ cells, or the NK cell population in normal mice (Webster et al., 2009; Dinh et al., 2012). This IL-2/IL-2Ab complex has been used in different animal models to reduce transplantation rejection (Webster et al., 2009; Koreth et al., 2011) and to treat experimental autoimmune 
A

B
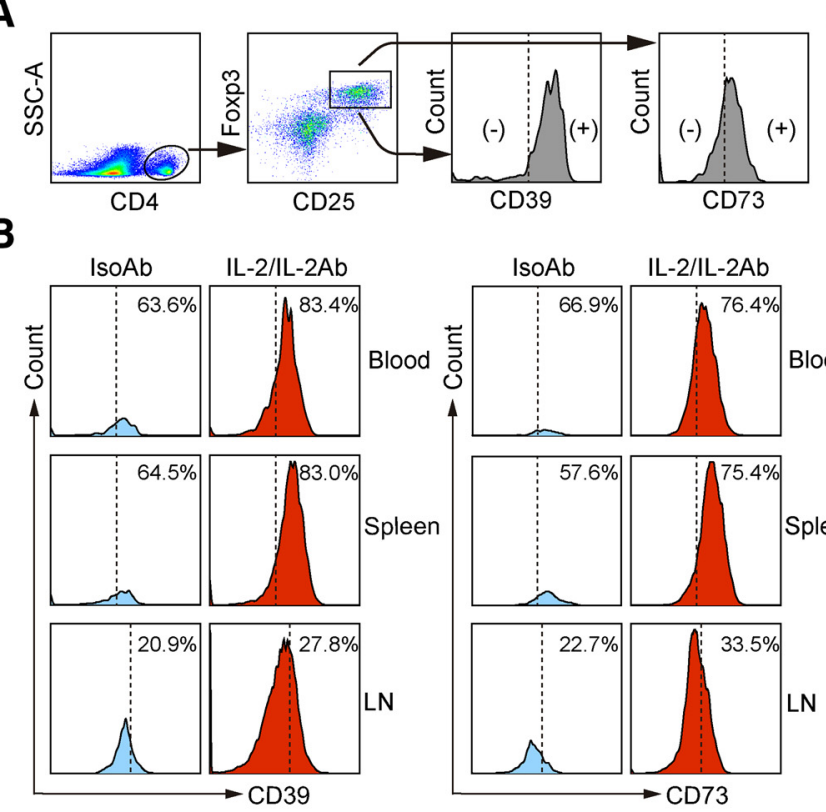

E

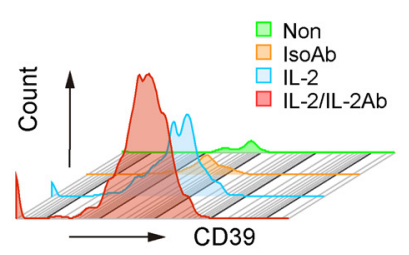

C
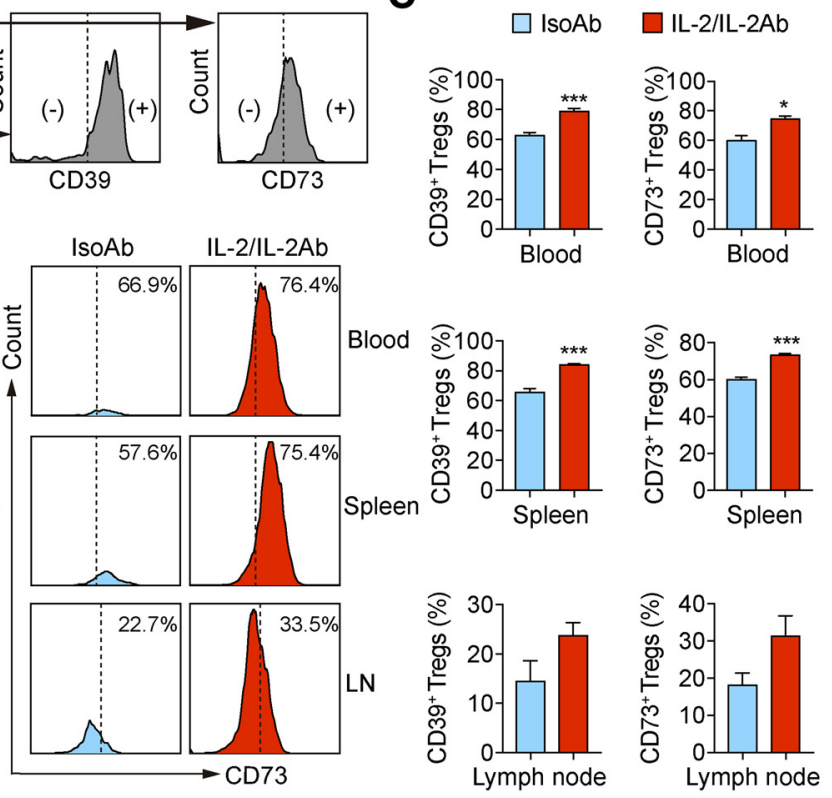

F
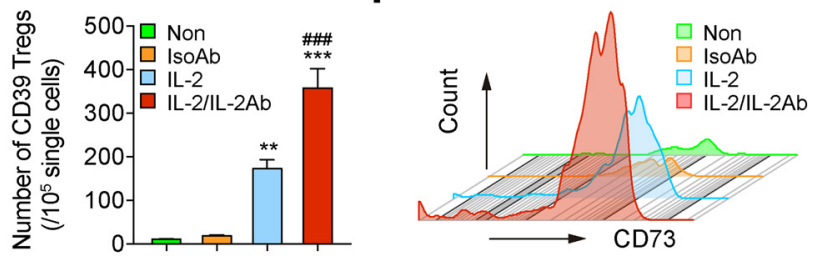

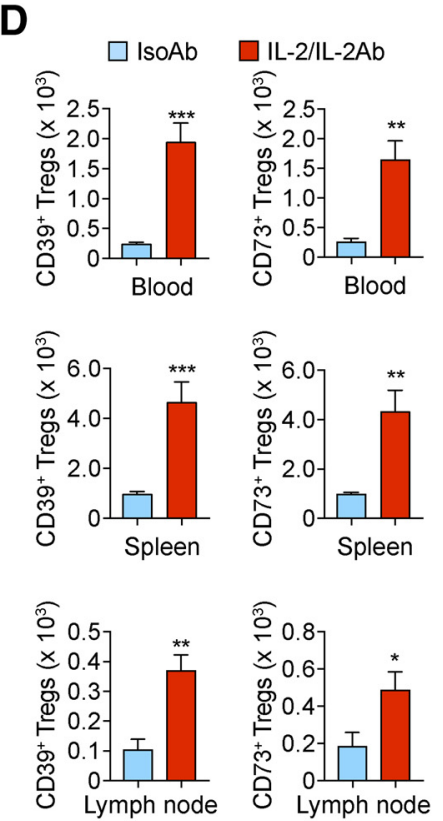

Figure 7. IL-2/IL-2Ab enhances CD39/CD73 signaling in expanded Tregs. $\boldsymbol{A}-\boldsymbol{C}, \mathrm{C} 57 \mathrm{BL} / 6$ mice were pretreated with IL-2/IL-2Ab or IsoAb intraperitoneally for $3 \mathrm{~d}$ before tMCA0. Mice were killed 3 dafter tMCA0. Blood, spleen, and lymph nodes (LNs) were collected for flow cytometry analysis. $\boldsymbol{A}$, Gating strategy for CD39 and CD73 expression on CD4 ${ }^{+}$CD25 ${ }^{+}$Foxp3 ${ }^{+}$Tregs. $\boldsymbol{B}$, Representative flow cytometry plots for CD39 (left) and CD73 (right) expression on $C D 4^{+}$CD25 ${ }^{+}$Foxp3 ${ }^{+}$Tregs in blood, spleen, and LNs. $\boldsymbol{C}, \boldsymbol{D}$, Percentages of CD39 ${ }^{+}$cells and CD73 ${ }^{+}$cells among $\mathrm{CD}^{+}{ }^{+} \mathrm{CD} 25^{+}{ }^{+}$Foxp3 ${ }^{+}$Tregs (C) and the number of CD39 ${ }^{+}$Tregs and $\mathrm{CD} 73^{+}$Tregs in $10^{5}$ lymphocytes $(\boldsymbol{D})$ in blood, spleen, and LNs were higher in the IL-2/IL-2Ab treatment group than those in the IsoAb treatment group. $n=7 /$ group for blood; $n=6-7 /$ group for spleen; $n=4 /$ group for LNs. ${ }^{*} p<0.05,{ }^{* *} p<0.01,{ }^{* * *} p<0.001 \mathrm{IL}-2 / \mathrm{IL}$-2Ab versus IsoAb. $\boldsymbol{E}, \boldsymbol{F}$, Equal numbers of splenocytes were treated with IsoAb, IL-2, IL-2/IL-2Ab, or without any treatment (Non) for $3 \mathrm{~d}$. Representative histogram plots for CD39(E) and CD73 (F) expression on CD4 ${ }^{+}$CD25 ${ }^{+}$Foxp3 ${ }^{+}$Tregs are shown. The numbers of $C D 39{ }^{+}$Tregs $(\boldsymbol{E})$ and $\operatorname{CD} 73^{+}$Tregs $(\boldsymbol{F})$ were quantified. $n=4 /$ group. ${ }^{* *} p<0.01,{ }^{* * *} p<0.001$ versus IsoAb and nontreated control; \#\#\#p $<0.001$ versus IL-2.

A

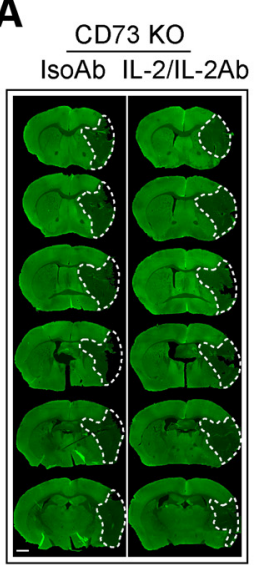

B
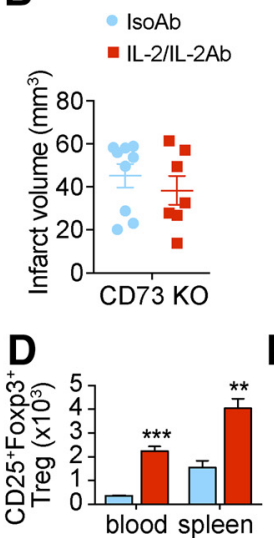

C $\frac{\mathrm{CD} 73 \mathrm{KO}}{\mathrm{ISOAb \quad \text {IL-2/L-2Ab }}}$

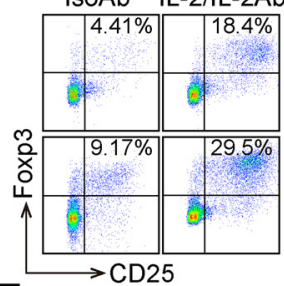

E

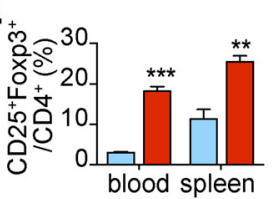

F

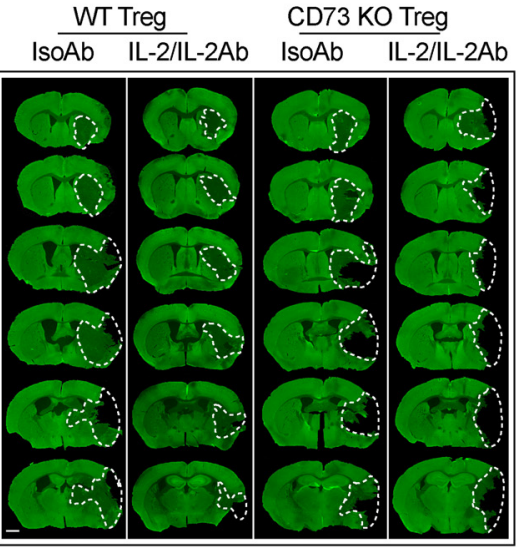

- WT-IsoAb

- WT-IL-2/IL-2Ab

- KO-IsoAb

$\checkmark \mathrm{KO}-\mathrm{IL}-2 / \mathrm{IL}-2 \mathrm{Ab}$

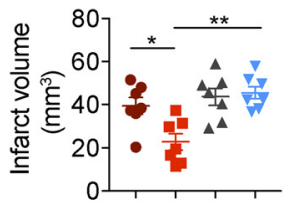

Figure 8. CD73 deficiency reduces the protective effect of Tregs. $A-E, C D 73 \mathrm{KO}$ mice were pretreated with IL-2/IL-2Ab or IsoAb intraperitoneally for $3 \mathrm{~d}$ before tMCA0. $\boldsymbol{A}, \boldsymbol{B}, \mathrm{Infarct}$ volume was measured by MAP2 immunostaining $3 \mathrm{~d}$ after tMCA0. $n=7-9 /$ group. Scale bar, $1 \mathrm{~mm}$. C $-\boldsymbol{E}$, Number of CD4 ${ }^{+}$CD25 ${ }^{+}$Foxp $3^{+}$Tregs in $10^{5}$ lymphocytes (D) and percentages of CD25 ${ }^{+}$Foxp3 ${ }^{+}$ Tregs among $\mathrm{CD}^{+}{ }^{+} \mathrm{T}$ cells $(\boldsymbol{E})$ in blood and spleen significantly increased in the IL-2/L-2Ab-treated group compared with the IsoAb-treated group $3 \mathrm{~d}$ after $\mathrm{tMCAO}$ in CD73 K0 mice. $n=3 /$ group. ${ }^{* *} p<0.01,{ }^{* * *} p<0.001$, IL-2/LL-2Ab versus IsoAb. F, Donor Tregs were isolated from C57BL/6 or CD73 KO mice pretreated with IL-2/LL-2Ab or IsoAb. Tregs were then transferred into recipient C57BL/6 WT mice through the tail vein $2 \mathrm{~h}$ after $\mathrm{MCA}$. Animals were killed $3 \mathrm{~d}$ after ischemic stroke for infarct volume measurement. Left, Representative images of MAP2 staining. Scale bar, $1 \mathrm{~mm}$. Right, Quantification of infarct volume. $n=7 /$ group. ${ }^{*} p<0.05,{ }^{* *} p<0.01$. 


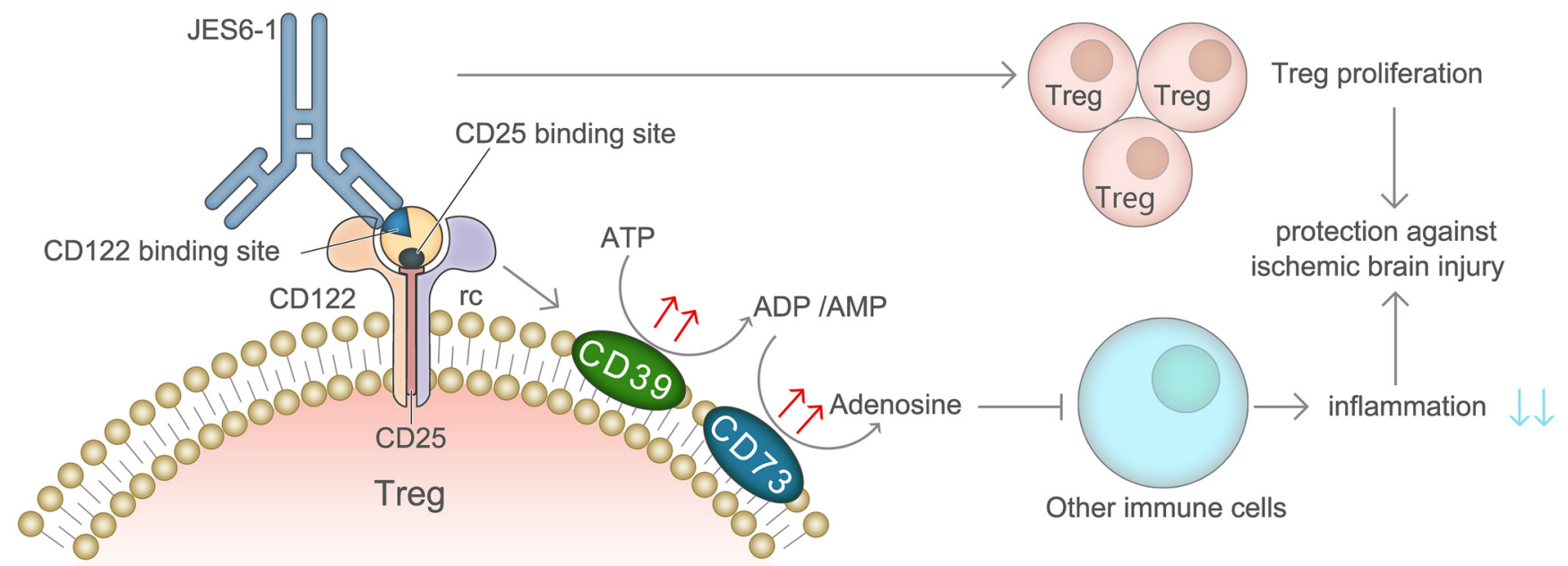

Figure 9. Schematic illustration of the mechanisms for IL-2/IL-2Ab-afforded protection to the ischemic brain. IL-2/LL-2Ab treatment protects against ischemic brain injury by selectively expanding the number of Tregs in vivo and boosts the immunomodulatory function of Tregs. Elevated expression of CD39/CD73 on Tregs is important for IL-2/L-2Ab-afforded neuroprotection. Detailed information about statistical analysis for each experiment is summarized in Table 9-1, available at https://doi.org/10.1523/JNEUROSCI.3411-17.2018.t9-1.

diseases such as diabetes (Manirarora and Wei, 2015) and lupus nephritis (Yan et al., 2017) and other disorders such as allergic contact dermatitis (El Beidaq et al., 2016), atherosclerosis (Dinh et al., 2012), congestive heart failure (Wang et al., 2016), and traumatic brain injury (Gao et al., 2017). Our study extended the application of IL-2/IL-2Ab into a CNS disease model and discovered a significant and selective boost in Treg numbers $3 \mathrm{~d}$ after tMCAO by IL-2/IL-2Ab treatment. Such Treg elevation is essential for the protective effect of IL-2/IL-2Ab against stroke because Treg depletion in DT-treated DTR mice eliminated IL-2/IL-2Abafforded protection against brain infarct.

Although our data show Treg-specific actions of IL-2/IL-2Ab with very limited off-target effects, the potential influence of IL2/IL-2Ab on other immune cell populations apart from Tregs should be considered. It was reported in an animal model of herpetic stromal keratitis that IL-2/IL-2Ab may increase the numbers of splenic NK cells (Gaddipati et al., 2015). However, we observed no change in the number of NK cells after IL-2/IL-2Ab treatment in stroke mice. Furthermore, because NK cells are reported to be detrimental to the ischemic brain (Gan et al., 2014), it is most unlikely that the protective effect of IL-2/IL-2Ab is due to increased number of NK cells. In addition, our results show that IL-2/IL-2Ab had no effect on the number of monocyte/macrophages in the periphery or the number of microglia in the ischemic brain $3 \mathrm{~d}$ after stroke. Interestingly, the number of infiltrating $\mathrm{CD} 45^{\text {high }} \mathrm{CD} 11 \mathrm{~b}^{+}$macrophages was reduced in the ischemic brain in IL-2/IL-2Ab-treated mice. Such a decrease may reflect alterations in the migratory ability and other functions of macrophages. Our data revealed no significant difference in the percentages of $\mathrm{Ly}_{6 \mathrm{C}}{ }^{+} \mathrm{CD} 115^{+}$monocytes/macrophages in the blood of IL-2/IL-2Ab-treated stroke mice, suggesting a minimal influence of IL-2/IL-2Ab on monocytes/macrophage phenotypes. Further functional studies are warranted to elucidate the influence of IL-2/IL-2Ab or IL-2/IL-2Ab-stimulated Tregs on monocytes/macrophages.

With increased knowledge about the beneficial roles of Tregs in the ischemic brain (Liesz et al., 2009; Li et al., 2013; Wang et al., 2015), more and more neuroprotective agents or approaches have been shown to possess the capacity to increase Treg popu- lation. For example, the adjustment of commensal microbiota before stroke attack led to an elevation of Tregs, which contributed to a prevention of stroke (Benakis et al., 2016). Consistent with this study, we showed that pretreatment with IL-2/IL-2Ab could reduce the severity of ischemic brain injury. We also evaluated the therapeutic potential of IL-2/IL-2Ab and showed that it ameliorated brain infarct and improved sensorimotor functions with treatment $2 \mathrm{~h}$ after stroke. Previous studies have revealed multifaceted mechanisms for Treg-afforded neuroprotection, including inhibition of Teffs (Liesz et al., 2009), regulation of microglia/macrophage activity (Zhao et al., 2012), and protection of the blood-brain barrier (Li et al., 2013). Here, we showed that IL-2/IL2Ab exerted potent anti-inflammatory effects in the ischemic brain. IL-2/IL2Ab treatment significantly reduced the infiltration of inflammatory cells and inhibited the elevation of cerebral inflammatory cytokines after stroke. There are controversial results in the literature showing either no effect (Ren et al., 2011) or even a detrimental effect (Kleinschnitz et al., 2013) of Tregs in the stroke model. It is likely that the therapeutic effects of Tregs rely on the type of stroke (transient or permanent, location, etc), the variance in stroke severity, and the dynamic nature of poststroke immunity (Liesz et al., 2015; Liesz and Kleinschnitz, 2016). Interestingly, two recent studies documented the effect of Tregs on neurogenesis (Wang et al., 2015) and myelination (Dombrowski et al., 2017) after CNS injury. Therefore, the effect of IL-2/IL-2Ab on long-term stroke recovery warrants further exploration.

We also discovered that IL-2/IL-2Ab not only expanded the number of Tregs, but also enhanced Treg function. Adoptive transfer of Tregs isolated from IL-2/IL-2Ab-treated mice provided more potent neuroprotection than an equal number of Tregs prepared from IsoAb-treated mice. In vitro studies confirmed that Tregs isolated from IL-2/IL-2Ab-treated mice have better immunosuppressive properties and a stronger capacity to inhibit the proliferation of Teffs compared with Tregs isolated from IsoAb-treated mice. We further found that IL-2/IL-2Ab may enhance Treg functions by increasing their expression of CD39 and CD73. The CD39/CD73 signaling axis, as a critical checkpoint for the balance of the immune-stimulating ATP and 
the immunosuppressive adenosine (Beavis et al., 2012), plays a critical role in the maintenance of immune homeostasis (Antonioli et al., 2013). CD39 and CD73 are both highly expressed on Foxp3 $^{+}$Tregs (Mandapathil et al., 2009; Sakaguchi et al., 2010; Schuler et al., 2011). IL-2/IL-2Ab treatment significantly increased the numbers of CD $39^{+}$Tregs and CD73 ${ }^{+}$Tregs in blood, spleen, and lymph nodes. It is known that adenosine produced by Tregs inhibits the generation of proinflammatory cytokines and chemokines from Teffs (Deaglio et al., 2007). In addition, adenosine could further promote Treg expansion (Ohta et al., 2012). Accordingly, the improved functions of IL-2/IL-2Ab-stimulated Tregs could be explained, at least partially, by their enhanced expression of CD39/CD73. Consistent with this notion, IL-2/IL$2 \mathrm{Ab}$ injection into CD73 KO mice, although it still expanded the number of Tregs, failed to show protection against ischemic stroke. Furthermore, genetic ablation of CD73 diminished the protective effect of IL-2/IL-2Ab-stimulated Tregs in stroke mice. The present study does not exclude the involvement of other mechanisms in the neuroprotective effect of IL-2/IL-2Abstimulated Tregs. For example, IL-2/IL-2Ab injection has been shown to increase the expression of some suppressive molecules such as cytotoxic T-lymphocyte-associated protein 4 (CTLA4) and glucocorticoid-induced TNFR-related protein (GITR) on splenic Tregs (Lee et al., 2012). Whether these molecules are induced by IL-2/IL-2Ab in stroke mice and their contribution to IL-2/IL-2Ab-afforded neuroprotection need to be explored in future studies.

Thymus-derived natural Tregs (nTregs) and induced Tregs (iTregs) are two main subsets of Tregs. nTregs and iTregs have similar phenotypic characteristics (they both express the canonical Treg markers, CD25, Foxp3, GITR, and CTLA4) and suppressive functions against $\mathrm{T}$-cell-mediated immune responses and diseases. These two subsets may exhibit some differences, such as different mRNA transcripts and protein expression. $\mathrm{He}-$ lios and Nrp1 are the two markers that are expressed at high levels in nTregs and could therefore distinguish nTregs and iTregs under normal conditions (Yadav et al., 2012). However, there are conflicting data demonstrating that neither Nrp1 nor Helios can unequivocally identify Treg clones of thymic or peripheral origin (Szurek et al., 2015). The effect of IL-2/IL-2Ab on Treg subsets under normal conditions has been reported previously (El Beidaq et al., 2016). IL-2/IL-2Ab significantly increased the percentages of Foxp $3^{+} \mathrm{Nrp}{ }^{-}$nTregs and Foxp $3^{+} \mathrm{Nrp}-1^{+}$iTregs among $\mathrm{CD}^{+}{ }^{+} \mathrm{T}$ cells (El Beidaq et al., 2016). Under inflammatory conditions, iTreg expresses some level of Nrp1 and become undistinguishable from nTregs (Singh et al., 2015). Therefore, whereas distinguishing between the functions of nTregs and iTregs might be important in the stroke setting, it is not practical due to the paucity of specific markers and may introduce confusion into data interpretation.

In summary, the current study demonstrates that IL-2/IL-2Ab protects against ischemic brain injury by selectively expanding the number of Tregs in vivo and also boosts the immunomodulatory function of Tregs by activating CD39/CD73 signaling (Fig. 9). Our results suggest that in vivo expansion of Tregs using IL2/IL-2Ab is a possible immune therapeutic strategy for stroke. Several recent clinical trials have shown promising results of lowdose human recombinant IL-2 to expand Tregs in vivo for the treatment of hepatitis $\mathrm{C}$ vasculitis and graft versus host disease (Saadoun et al., 2011; Rosenzwajg et al., 2015). The clinical trials also showed the safety of low-dose IL-2 in multiple autoimmune diseases. However, some off-target effects were reported in some clinical trials even using a very low dose of IL-2 (Pham et al.,
2015). The addition of a specific IL-2 antibody that enhances the Treg-specific action might be an approach to increase the effectiveness and reduce the side effects of IL-2 treatment. So far, there have been no clinical trials of the influence of IL-2/IL-2Ab complex in human diseases. Further studies are warranted to understand the immunological differences between rodents and humans and to evaluate the translational potential of the IL-2/IL$2 \mathrm{Ab}$ complex for clinical stroke treatment.

\section{References}

Antonioli L, Pacher P, Vizi ES, Haskó G (2013) CD39 and CD73 in immunity and inflammation. Trends Mol Med 19:355-367. CrossRef Medline

Battaglia M, Stabilini A, Migliavacca B, Horejs-Hoeck J, Kaupper T, Roncarolo MG (2006) Rapamycin promotes expansion of functional CD4+CD25+FOXP3 + regulatory $\mathrm{T}$ cells of both healthy subjects and type 1 diabetic patients. J Immunol 177:8338-8347. CrossRef Medline

Beavis PA, Stagg J, Darcy PK, Smyth MJ (2012) CD73: a potent suppressor of antitumor immune responses. Trends Immunol 33:231-237. CrossRef Medline

Benakis C, Brea D, Caballero S, Faraco G, Moore J, Murphy M, Sita G, Racchumi G, Ling L, Pamer EG, Iadecola C, Anrather J (2016) Commensal microbiota affects ischemic stroke outcome by regulating intestinal gammadelta T cells. Nat Med 22:516-523. CrossRef Medline

Boyman O, Kovar M, Rubinstein MP, Surh CD, Sprent J (2006) Selective stimulation of $\mathrm{T}$ cell subsets with antibody-cytokine immune complexes. Science 311:1924-1927. CrossRef Medline

Deaglio S, Dwyer KM, Gao W, Friedman D, Usheva A, Erat A, Chen JF, Enjyoji K, Linden J, Oukka M, Kuchroo VK, Strom TB, Robson SC (2007) Adenosine generation catalyzed by CD39 and CD73 expressed on regulatory T cells mediates immune suppression. J Exp Med 204:12571265. CrossRef Medline

Dinh TN, Kyaw TS, Kanellakis P, To K, Tipping P, Toh BH, Bobik A, Agrotis A (2012) Cytokine therapy with interleukin-2/anti-interleukin-2 monoclonal antibody complexes expands CD4 + CD25+Foxp3 + regulatory $\mathrm{T}$ cells and attenuates development and progression of atherosclerosis. Circulation 126:1256-1266. CrossRef Medline

Dombrowski Y, O’Hagan T, Dittmer M, Penalva R, Mayoral SR, Bankhead P, Fleville S, Eleftheriadis G, Zhao C, Naughton M, Hassan R, Moffat J, Falconer J, Boyd A, Hamilton P, Allen IV, Kissenpfennig A, Moynagh PN, Evergren E, Perbal B, et al. (2017) Regulatory T cells promote myelin regeneration in the central nervous system. Nat Neurosci 20:674-680. CrossRef Medline

ElAli A, Jean LeBlanc N (2016) The role of monocytes in ischemic stroke pathobiology: new avenues to explore. Front Aging Neurosci 8:29. CrossRef Medline

El Beidaq A, Link CW, Hofmann K, Frehse B, Hartmann K, Bieber K, Martin SF, Ludwig RJ, Manz RA (2016) In vivo expansion of endogenous regulatory $\mathrm{T}$ cell populations induces long-term suppression of contact hypersensitivity. J Immunol 197:1567-1576. CrossRef Medline

Fontenot JD, Rudensky AY (2005) A well adapted regulatory contrivance: regulatory $\mathrm{T}$ cell development and the forkhead family transcription factor Foxp3. Nat Immunol 6:331-337. CrossRef Medline

Gaddipati S, Estrada K, Rao P, Jerome AD, Suvas S (2015) IL-2/anti-IL-2 antibody complex treatment inhibits the development but not the progression of herpetic stromal keratitis. J Immunol 194:273-282. CrossRef Medline

Gan Y, Liu Q, Wu W, Yin JX, Bai XF, Shen R, Wang Y, Chen J, La Cava A, Poursine-Laurent J, Yokoyama W, Shi FD (2014) Ischemic neurons recruit natural killer cells that accelerate brain infarction. Proc Natl Acad Sci U S A 111:2704-2709. CrossRef Medline

Gao W, Li F, Zhou Z, Xu X, Wu Y, Zhou S, Yin D, Sun D, Xiong J, Jiang R, Zhang J (2017) IL-2/Anti-IL-2 complex attenuates inflammation and BBB disruption in mice subjected to traumatic brain injury. Front Neurol 8:281. CrossRef Medline

Golshayan D, Jiang S, Tsang J, Garin MI, Mottet C, Lechler RI (2007) In vitro-expanded donor alloantigen-specific $\mathrm{CD} 4+\mathrm{CD} 25+$ regulatory $\mathrm{T}$ cells promote experimental transplantation tolerance. Blood 109:827835. CrossRef Medline

Hori S, Nomura T, Sakaguchi S (2003) Control of regulatory T cell development by the transcription factor Foxp3. Science 299:1057-1061. CrossRef Medline 
Kim JM, Rasmussen JP, Rudensky AY (2007) Regulatory T cells prevent catastrophic autoimmunity throughout the lifespan of mice. Nat Immunol 8:191-197. CrossRef Medline

Kleinschnitz C, Kraft P, Dreykluft A, Hagedorn I, Göbel K, Schuhmann MK, Langhauser F, Helluy X, Schwarz T, Bittner S, Mayer CT, Brede M, Varallyay C, Pham M, Bendszus M, Jakob P, Magnus T, Meuth SG, Iwakura Y, Zernecke A, et al. (2013) Regulatory T cells are strong promoters of acute ischemic stroke in mice by inducing dysfunction of the cerebral microvasculature. Blood 121:679-691. CrossRef Medline

Koreth J, Matsuoka K, Kim HT, McDonough SM, Bindra B, Alyea EP 3rd, Armand P, Cutler C, Ho VT, Treister NS, Bienfang DC, Prasad S, Tzachanis D, Joyce RM, Avigan DE, Antin JH, Ritz J, Soiffer RJ (2011) Interleukin-2 and regulatory T cells in graft-versus-host disease. $\mathrm{N}$ Engl J Med 365:2055-2066. CrossRef Medline

Lee SY, Cho ML, Oh HJ, Ryu JG, Park MJ, Jhun JY, Park MK, Stone JC, Ju JH, Hwang SY, Park SH, Surh CD, Kim HY (2012) Interleukin-2/antiinterleukin-2 monoclonal antibody immune complex suppresses collagen-induced arthritis in mice by fortifying interleukin-2/STAT5 signalling pathways. Immunology 137:305-316. CrossRef Medline

Li P, Gan Y, Sun BL, Zhang F, Lu B, Gao Y, Liang W, Thomson AW, Chen J, Hu X (2013) Adoptive regulatory T-cell therapy protects against cerebral ischemia. Ann Neurol 74:458-471. CrossRef Medline

Li P, Mao L, Liu X, Gan Y, Zheng J, Thomson AW, Gao Y, Chen J, Hu X (2014) Essential role of program death 1-ligand 1 in regulatory T-cellafforded protection against blood-brain barrier damage after stroke. Stroke 45:857-864. CrossRef Medline

Liesz A, Hu X, Kleinschnitz C, Offner H (2015) Functional role of regulatory lymphocytes in stroke: facts and controversies. Stroke 46:1422-1430. CrossRef Medline

Liesz A, Kleinschnitz C (2016) Regulatory T cells in post-stroke immune homeostasis. Transl Stroke Res 7:313-321. CrossRef Medline

Liesz A, Suri-Payer E, Veltkamp C, Doerr H, Sommer C, Rivest S, Giese T, Veltkamp R (2009) Regulatory T cells are key cerebroprotective immunomodulators in acute experimental stroke. Nat Med 15:192-199. CrossRef Medline

Mandapathil M, Lang S, Gorelik E, Whiteside TL (2009) Isolation of functional human regulatory $\mathrm{T}$ cells (Treg) from the peripheral blood based on the CD39 expression. J Immunol Methods 346:55-63. CrossRef Medline

Manirarora JN, Wei CH (2015) Combination therapy using IL-2/IL-2 monoclonal antibody complexes, rapamycin, and islet autoantigen peptides increases regulatory $\mathrm{T}$ cell frequency and protects against spontaneous and induced type 1 diabetes in nonobese diabetic mice. J Immunol 195:5203-5214. CrossRef Medline

Mao L, Li P, Zhu W, Cai W, Liu Z, Wang Y, Luo W, Stetler RA, Leak RK, Yu W, Gao Y, Chen J, Chen G, Hu X (2017) Regulatory T cells ameliorate tissue plasminogen activator-induced brain haemorrhage after stroke. Brain 140:1914-1931. CrossRef Medline

McDonald-Hyman C, Flynn R, Panoskaltsis-Mortari A, Peterson N, MacDonald KP, Hill GR, Luznik L, Serody JS, Murphy WJ, Maillard I, Munn DH, Turka LA, Koreth J, Cutler CS, Soiffer RJ, Antin JH, Ritz J, Blazar BR (2016) Therapeutic regulatory T-cell adoptive transfer ameliorates established murine chronic GVHD in a CXCR5-dependent manner. Blood 128:1013-1017. CrossRef Medline

Ohta A, Kini R, Ohta A, Subramanian M, Madasu M, Sitkovsky M (2012) The development and immunosuppressive functions of $\mathrm{CD} 4(+)$ $\mathrm{CD} 25(+)$ FoxP3(+) regulatory $\mathrm{T}$ cells are under influence of the adenosine-A2A adenosine receptor pathway. Front Immunol 3:190. CrossRef Medline

Pham MN, von Herrath MG, Vela JL (2015) Antigen-specific regulatory T cells and low dose of IL-2 in treatment of type 1 diabetes. Front Immunol 6:651. CrossRef Medline

Ren X, Akiyoshi K, Vandenbark AA, Hurn PD, Offner H (2011) $\mathrm{CD} 4+$ FoxP3 + regulatory T-cells in cerebral ischemic stroke. Metab Brain Dis 26:87-90. CrossRef Medline

Rosenzwajg M, Churlaud G, Mallone R, Six A, Dérian N, Chaara W, Lorenzon R, Long SA, Buckner JH, Afonso G, Pham HP, Hartemann A, Yu A, Pugliese A, Malek TR, Klatzmann D (2015) Low-dose interleukin-2 fosters a dose-dependent regulatory $\mathrm{T}$ cell tuned milieu in T1D patients. J Autoimmun 58:48-58. CrossRef Medline
Saadoun D, Rosenzwajg M, Joly F, Six A, Carrat F, Thibault V, Sene D, Cacoub P, Klatzmann D (2011) Regulatory T-cell responses to low-dose interleukin-2 in HCV-induced vasculitis. N Engl J Med 365:2067-2077. CrossRef Medline

Sakaguchi S, Miyara M, Costantino CM, Hafler DA (2010) FOXP3+ regulatory T cells in the human immune system. Nat Rev Immunol 10:490500. CrossRef Medline

Schuler PJ, Harasymczuk M, Schilling B, Lang S, Whiteside TL (2011) Separation of human $\mathrm{CD} 4+\mathrm{CD} 39+\mathrm{T}$ cells by magnetic beads reveals two phenotypically and functionally different subsets. J Immunol Methods 369:59-68. CrossRef Medline

Shevach EM (2012) Application of IL-2 therapy to target T regulatory cell function. Trends Immunol 33:626-632. CrossRef Medline

Singh K, Hjort M, Thorvaldson L, Sandler S (2015) Concomitant analysis of helios and neuropilin-1 as a marker to detect thymic derived regulatory $\mathrm{T}$ cells in naive mice. Sci Rep 5:7767. CrossRef Medline

Szurek E, Cebula A, Wojciech L, Pietrzak M, Rempala G, Kisielow P, Ignatowicz L (2015) Differences in expression level of helios and neuropilin-1 do not distinguish thymus-derived from extrathymically-induced CD4+Foxp3+ regulatory T cells. PLoS One 10:e0141161. CrossRef Medline

Tang Q, Henriksen KJ, Bi M, Finger EB, Szot G, Ye J, Masteller EL, McDevitt $\mathrm{H}$, Bonyhadi M, Bluestone JA (2004) In vitro-expanded antigen-specific regulatory T cells suppress autoimmune diabetes. J Exp Med 199:14551465. CrossRef Medline

Tomala J, Chmelova H, Mrkvan T, Rihova B, Kovar M (2009) In vivo expansion of activated naive CD8 + T cells and NK cells driven by complexes of IL-2 and anti-IL-2 monoclonal antibody as novel approach of cancer immunotherapy. J Immunol 183:4904-4912. CrossRef Medline

Trzonkowski P, Szaryńska M, Myśliwska J, Myśliwski A (2009) Ex vivo expansion of $\mathrm{CD} 4(+) \mathrm{CD} 25(+) \mathrm{T}$ regulatory cells for immunosuppressive therapy. Cytometry A 75:175-188. CrossRef Medline

Urra X, Cervera A, Villamor N, Planas AM, Chamorro A (2009) Harms and benefits of lymphocyte subpopulations in patients with acute stroke. Neuroscience 158:1174-1183. CrossRef Medline

Wang H, Hou L, Kwak D, Fassett J, Xu X, Chen A, Chen W, Blazar BR, Xu Y, Hall JL, Ge JB, Bache RJ, Chen Y (2016) Increasing regulatory T cells with interleukin-2 and interleukin-2 antibody complexes attenuates lung inflammation and heart failure progression. Hypertension 68:114-122. CrossRef Medline

Wang J, Xie L, Yang C, Ren C, Zhou K, Wang B, Zhang Z, Wang Y, Jin K, Yang GY (2015) Activated regulatory $T$ cell regulates neural stem cell proliferation in the subventricular zone of normal and ischemic mouse brain through interleukin 10. Front Cell Neurosci 9:361. CrossRef Medline

Webster KE, Walters S, Kohler RE, Mrkvan T, Boyman O, Surh CD, Grey ST, Sprent J (2009) In vivo expansion of T reg cells with IL-2-mAb complexes: induction of resistance to EAE and long-term acceptance of islet allografts without immunosuppression. J Exp Med 206:751-760. CrossRef Medline

Yadav M, Louvet C, Davini D, Gardner JM, Martinez-Llordella M, BaileyBucktrout S, Anthony BA, Sverdrup FM, Head R, Kuster DJ, Ruminski P, Weiss D, Von Schack D, Bluestone JA (2012) Neuropilin-1 distinguishes natural and inducible regulatory $\mathrm{T}$ cells among regulatory $\mathrm{T}$ cell subsets in vivo. J Exp Med 209:1713-1722, S1-S19. CrossRef Medline

Yan J, Greer JM, Etherington K, Cadigan GP, Cavanagh H, Henderson RD, O'Sullivan JD, Pandian JD, Read SJ, McCombe PA (2009) Immune activation in the peripheral blood of patients with acute ischemic stroke. J Neuroimmunol 206:112-117. CrossRef Medline

Yan JJ, Lee JG, Jang JY, Koo TY, Ahn C, Yang J (2017) IL-2/anti-IL-2 complexes ameliorate lupus nephritis by expansion of CD4+CD25+Foxp3+ regulatory T cells. Kidney Int 91:603-615. CrossRef Medline

Yang Y, Liu H, Zhang H, Ye Q, Wang J, Yang B, Mao L, Zhu W, Leak RK, Xiao B, Lu B, Chen J, Hu X (2017) ST2/IL-33-dependent microglial response limits acute ischemic brain injury. J Neurosci 37:4692-4704. CrossRef Medline

Zhao W, Beers DR, Liao B, Henkel JS, Appel SH (2012) Regulatory T lymphocytes from ALS mice suppress microglia and effector T lymphocytes through different cytokine-mediated mechanisms. Neurobiol Dis 48: 418-428. CrossRef Medline 